\title{
The Behavior of Mean Zonal Wind and Planetary-Scale Disturbances in the Troposphere and Stratosphere during the 1973 Sudden Warming
}

\author{
By Hiroshi Kanzawa \\ Geophysical Institute, Kyoto University, Kyoto 606, Japan \\ (Manuscript received 29 February 1980, in revised form 23 June 1980)
}

\begin{abstract}
The behavior of mean zonal wind and planetary-scale geopotential height disturbances during the 1973 sudden warming is investigated in terms of their dynamical interactions, with use of the data of Nimbus 5 Selective Chopper Radiometer and conventional radiosonde. From the survey of the stratospheric temperature field in the 1972/73 northern hemisphere winter, it is found that two mid-winter warmings occurred successively at an interval of about 16 days. Examination of previous studies based on satellite observations reveals that a major or minor warming occurs about two weeks before a spectacular major warming, and an emphasis is laid on the effect of the first warming on the second one.

A large easterly region of mean zonal wind appeared in the stratospheric high latitudes in the second warming (Warming 2) while not in the first warming (Warming 1). With Warming 2, initially the easterly accelerations occurred in middle latitudes while the westerly accelerations in high latitudes in the upper stratosphere and these accelerations owe its existence generally to the momentum flux convergence mainly by wavenumber 2 disturbances. Eventually there occurred the intense easterly accelerations both in middle and high latitudes which brought about the circulation reversal in the stratosphere, which were due to the predominance of the Coriolis torque acting on the equatorward mean meridional flow induced mainly by wavenumber 1 disturbances. During pre-warming period for Warming 2, wavenumber 1 geopotential height disturbances propagated from the lower troposphere upward to the middle stratosphere and attained very large amplitude. This amplification of wavenumber 1 seems to come from the response to a characteristic mean zonal wind profile which continued through about 10 days after Warming 1 . The wind profile is such that a westerly maximum lies in the high latitudes $40 \mathrm{~km}$ level and then a region of large positive $\beta$-effective (latitudinal gradient of zonal mean quasi-geostrophic potential vorticity) in the high latitude stratosphere is surrounded by negative $\beta$-effective regions. It is speculated that this wavenumber 1 amplification is the result of resonance of planetary Rossby wave discussed by Tung and Lnidzen (1979).
\end{abstract}

\section{Introduction}

In the last two decades the studies on sudden warmings have been developed observationally, theoretically and numerically and they were reviewed by many authors (e.g., Holton, 1975; Schoeberl, 1978; McInturff, 1978). However previous observational studies were mainly based on conventional radiosonde data below about $10 \mathrm{mb}$ (ca. $30 \mathrm{~km}$ ). In recent years, the Selective Chopper Radiometer (SCR) on Nimbus 4 and 5 satellite (Houghton and Smith, 1970; Abel et al., 1970; Ellis et al., 1973) has provided us with global data of radiance up to the lower mesosphere. By using raw radiance data, the dynamics of the stratosphere was studied by many authors in terms of zonal harmonic component of planetary waves. The study of mean zonal wind and planetary-scale geopotential height disturbances in the stratosphere using geopotential heights retrieved from satellite radiance data was first performed by Hartmann (1976) who treated the southern hemispheric circulation in late winter 1973. Quite recently, Crane (1979) made the study concerned mainly with the energetical aspects of the stratosphere during the 1973 major 
stratospheric sudden warming. In the present study the same 1973 warming will be studied with an emphasis on the behavior of mean zonal wind and planetary-scale disturbances and their dynamical interactions. Crane (1979) treated only the region above the $50 \mathrm{mb}$ level, while in the present study is treated the region including not only the stratosphere but also the troposphere and we extended the period of analysis. By extending the region we can discuss the relation between the troposphere and stratosphere during the sudden warming. By extending the period of analysis we can cover two warmings which occurred successively at an interval of about 16 days (see Section 3) while Crane treated only the second warming and then we can discuss the effect of the first warming (Warming 1) on the second warming (Warming 2).

As regards the mechanism of the sudden warming, Matsuno (1971) proposed a model that the sudden warming can be accounted for in terms of planetary wave-mean flow interactions. It is desired for understanding of this phenomenon to describe how mean zonal winds and planetaryscale disturbances behave in the real atmosphere. However the behavior of them from the lower troposphere up to the stratopause level has not been well described so far. The description for the 1973 warming case is, therefore, performed in section 4 to give answers to the following questions. How appeared the mean zonal easterly winds accompanying the meridional temperature gradient reversal in the sudden polar warming? Did the easterly region descend? Which zonal wavenumber disturbance became intense during the easterly accelerations? Can we see upward propagation of planetary-scale disturbances from the troposphere? Can we see any characteristics of mean zonal wind profile before the amplification of the disturbances?

Matsuno (1971) deduced a mechanism how the sudden warming occurs if large-scale planetary waves amplify rapidly in the troposphere, on the basis of theoretical studies by Charney and Drazin (1961) and Eliassen and Palm (1960). According to him, the deceleration of the stratospheric zonal flow during the sudden warming is brought about by the Coriolis torque acting on the equatorward mean meridional flow induced by the vertically propagating planetary waves. Thus, Matsuno did not discuss explicitly the role of eddy momentum flux convergence in the easterly acceleration of zonal flow. By using a primitive equation model Holton (1976) showed that the zonal acceleration was a small residual of the opposing effects of the eddy momentum flux convergence and Coriolis torque. In the study of the spectacular event of 1976/77 major sudden warming, O'Neill and Taylor (1979) showed that the export of momentum from high latitudes by planetaryscale waves was crucial in effecting a zonal wind reversal in both the troposphere and lower stratosphere. In the energetical aspects during the 1973 warming, Crane (1979) discussed the importance of eddy momentum transport in the upper stratosphere. On the basis of zonal mean eastward momentum equation, we discuss the contribution of momentum flux convergence term and Coriolis term to the mean flow accelerations in section 5 .

Concerning the initiation of the sudden warming, Matsuno (1971) specified in his numerical model an observed wave forcing at the bottom of the stratosphere as a lower boundary condition. An important feature of the forcing function that he used is that of wave amplification preceding the warming. Therefore the question as to why certain waves are amplified preceding a warming event is very important to understand the cause of the phenomenon. By using a $\beta$ plane model with mean winds only varying with height, Tung and Lindzen (1979) proposed that the amplification of planetary waves is due to resonance: in order for resonance to occur, the large-scale waves must be trapped below the middle stratosphere and the trapping would occur effectively in the mean winds with negative vertical shear which has a tendency to make $\beta$ effective negative. Therefore in section 6 we investigate the wind conditions that prevailed before warmings in terms of $\beta$-effective (latitudinal gradient of zonal mean quasi-geostrophic potential vorticity).

\section{Data and treatment}

The principal data used in the present study are the gridded radiance data from the Nimbus 5 Selective Chopper Radiometer (SCR) channels $\mathrm{B} 12, \mathrm{~B} 23, \mathrm{~B} 34$ and $\mathrm{A} 1$, peaking around $1.5 \mathrm{mb}$ (ca. $43 \mathrm{~km}$ ), $3.5 \mathrm{mb}$ (ca. $38 \mathrm{~km}$ ), $8 \mathrm{mb}$ (ca. 33 $\mathrm{km}$ ) and $60 \mathrm{mb}$ (ca. $19 \mathrm{~km}$ ), respectively (see Barnett et al., 1975). The northern hemispheric NMC geopotential heights based on conventional radiosonde observations are used below $100 \mathrm{mb}$. Rocket sounding data are also used for thickness retrievals from the SCR data.

As Quiroz and Gelman (1972) discussed, thickness is the meteorological quantity nearest to radiance since the radiance for certain channel 
is a weighted average of Planck function over a layer of the atmosphere. Geopotential heights can be directly obtained by adding the thickness to the base height fields. In his study on the structure of the southern hemisphere winter stratosphere using SCR data, Hartmann (1976) showed that the estimated geopotential heights have less error than temperatures. Therefore in this study a multiple linear regression of the form

$$
\Delta Z_{i}=\sum_{j=1}^{4} A_{i j} T_{j}+B_{i}
$$

is used to determine the thickness $\Delta Z_{i}$ between $100 \mathrm{mb}$ and $i$-th pressure level from the radiance equivalent black-body temperatures $T_{1}, T_{2}, T_{3}$ and $T_{4}$ for channels B12, B23, B34 and A1, respectively. In order to obtain the regression coefficients $A_{i j}$ and $B_{i}$, meteorological rocket observation data at several stations from day 2 (Jan. 2) to day 43 (Feb. 12) of 1973 are used as reference values. Thus geopotential height grid point data (every $10^{\circ}$ in longitude and every $4^{\circ}$ in latitude from $20^{\circ} \mathrm{N}$ to $80^{\circ} \mathrm{N}$ ) are obtained at 22 levels $(850 \mathrm{mb}, 700 \mathrm{mb}, 500 \mathrm{mb}, 400 \mathrm{mb}, 300$ $\mathrm{mb}, 250 \mathrm{mb}, 200 \mathrm{mb}, 150 \mathrm{mb}, 100 \mathrm{mb}, 70 \mathrm{mb}$, $50 \mathrm{mb}, 30 \mathrm{mb}, 20 \mathrm{mb}, 10 \mathrm{mb}, 7 \mathrm{mb}, 5 \mathrm{mb}, 3 \mathrm{mb}$, $2 \mathrm{mb}, 1 \mathrm{mb}, 0.7 \mathrm{mb}, 0.4 \mathrm{mb}$ and $0.3 \mathrm{mb}$ ) in the troposphere, stratosphere and lower mesosphere on daily basis from day 2 (Jan. 2) to day 51 (Feb. 20) of 1973. Mean zonal winds are calculated geostrophically from the heights and planetary-scale geopotential height disturbances are analyzed by zonal Fourier harmonics.

Table 1 gives the obtained regression coefficients and standard error of estimates. The standard errors of the thickness above $1 \mathrm{mb}$ exceed 30 decameters. But the error of estimated mean zonal winds would become a few $\mathrm{m} \mathrm{s}^{-1}$ because the error is reduced by zonal averaging. On the other hand, zonal Fourier harmonic components of geopotential height are considered to be sufficiently accurate for the discussions in the following sections since the amplitude of wavenumber 1 and 2 become 100-200 decameters. Fig. 1 shows the wind velocities observed by rockets at Fort Churchill $\left(59^{\circ} \mathrm{N}, 94^{\circ} \mathrm{W}\right)$ and White Sands $\left(32^{\circ} \mathrm{N}, 106^{\circ} \mathrm{W}\right)$, together with the calculated geostrophic winds at the same locations at $2 \mathrm{mb}$. There is much correspondence between the estimated geostrophic winds and the rocket winds.

\section{Zonal mean temperature}

General features of the zonal mean circulation during the period of $1972 / 73$ northern hemisphere winter will be briefly described here in terms of the zonal mean raw radiance. Fig. 2 shows time variations of zonal mean radiance at $80^{\circ} \mathrm{N}$ for channcls B12, B23, B34 and A1 from day 348 (Dec. 13), 1972 to day 90 (Mar. 31), 1973. The interval of radiance unit (mWatt $\left.\mathrm{m}^{-2} \operatorname{ster}^{-1}\left(\mathrm{~cm}^{-1}\right)^{-1}\right)$ is almost equal to one degree Kelvin of equivalent black-body temperature, so the variation of radiances can be regarded as that of the mean temperatures of a certain layer corresponding to each channel's weighting functions (see Barnett et al., 1975). In this winter there occurred two warmings; for channel B12 one had its peak around day 13, 1973 (hereafter named Warming 1) and the other

Table 1. Regression coefficients $A_{i j}(j=1,4), B_{i}$, standard errors of estimate (meters) and number of sample used for regression. $\Delta Z_{i}$ is measured in meters and radiance equivalent black-body temperatures $T_{j}(j=1,4)$ in ${ }^{\circ} \mathrm{K}$ (see equation (1)).

\begin{tabular}{|c|c|c|c|c|c|c|c|}
\hline \multirow{2}{*}{$\begin{array}{l}\text { Layer } \\
(\mathrm{mb})\end{array}$} & \multicolumn{5}{|c|}{ Regression coefficients } & \multirow{2}{*}{$\begin{array}{l}\text { Standard } \\
\text { error } \\
\text { (m) }\end{array}$} & \multirow{2}{*}{$\begin{array}{l}\text { Number } \\
\text { of sample }\end{array}$} \\
\hline & $A_{1}$ & $A_{2}$ & $\mathbf{A}_{3}$ & $\mathrm{~A}_{4}$ & B & & \\
\hline $100-0.3$ & 54.83 & -35.86 & 111.80 & -42.42 & 18944 & 365 & 50 \\
\hline $100-0.4$ & 36.70 & -5.12 & 103.21 & -31.18 & 13508 & 358 & 119 \\
\hline $100-0.7$ & 4.19 & 5.26 & 118.05 & -17.61 & 8224 & 323 & 122 \\
\hline $100-1$ & -32.43 & 32.12 & 113.31 & -19.82 & 9634 & 306 & 126 \\
\hline $100-2$ & -76.22 & 34.83 & 126.51 & -35.12 & 14755 & 254 & 126 \\
\hline $100-3$ & -75.75 & 22.82 & 113.67 & -17.53 & 13488 & 237 & 127 \\
\hline $100-5$ & -63.06 & 6.99 & 81.48 & 17.84 & 10131 & 197 & 128 \\
\hline $100-7$ & -43.38 & -14.39 & 63.83 & 37.59 & 7774 & 177 & 128 \\
\hline $100-10$ & -21.26 & -24.55 & 27.98 & 68.24 & 3854 & 144 & 128 \\
\hline $100-20$ & -0.29 & -20.31 & -19.93 & 91.37 & -833 & 93 & 128 \\
\hline $100-30$ & 8.89 & -17.75 & -37.01 & 94.30 & -2961 & 70 & 128 \\
\hline $100-50$ & 7.97 & -9.12 & -34.43 & 65.36 & -2124 & 76 & 128 \\
\hline $100-70$ & 4.35 & -4.30 & -20.55 & 34.86 & -870 & 48 & 128 \\
\hline
\end{tabular}


around day 29, 1973 (named Warming 2). Warm- channel B34 changed from $48.8\left(223.2^{\circ} \mathrm{K}\right)$ on ing 2 occurred more suddenly than Warming 1 day 26 to $79.5\left(251.5^{\circ} \mathrm{K}\right)$ on day 30 , with an for all these channels. Regarding the rate of averaged rate of 7.7 radiance units per day. This radiance increase in Warming 2, the radiance at temperature rise rate is almost equal to that in

Fort Churchill

$59 \mathrm{~N} 94 \mathrm{~W}$
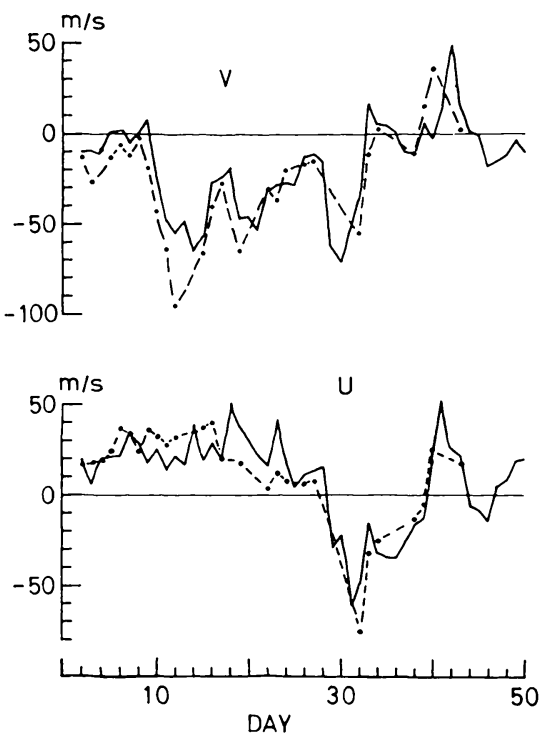

(a)
White Sands

$32 \mathrm{~N} 106 \mathrm{~W}$
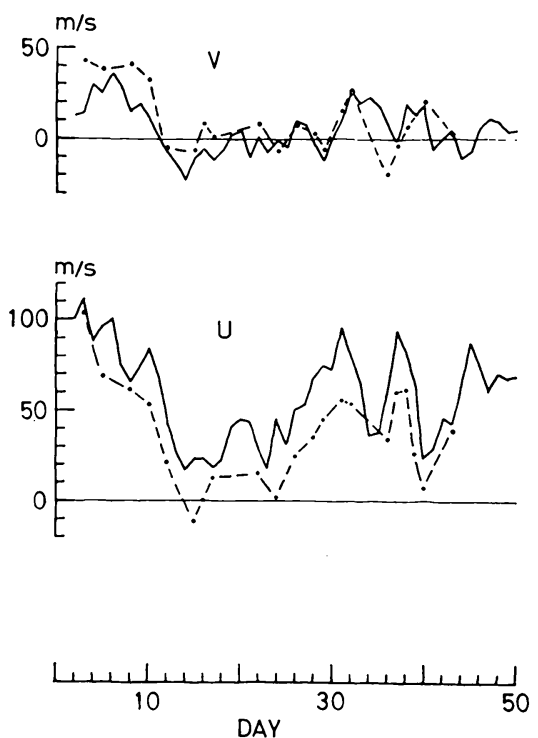

(b)

Fig. 1 Time variations of the winds observed by rockets (united by broken lines) at Fort Churchill (a) and White Sands (b) compared with satellite-derived geostrophic winds at the same locations (solid lines) at $2 \mathrm{mb} . v$ denotes northward velocity and $u$ eastward velocity.

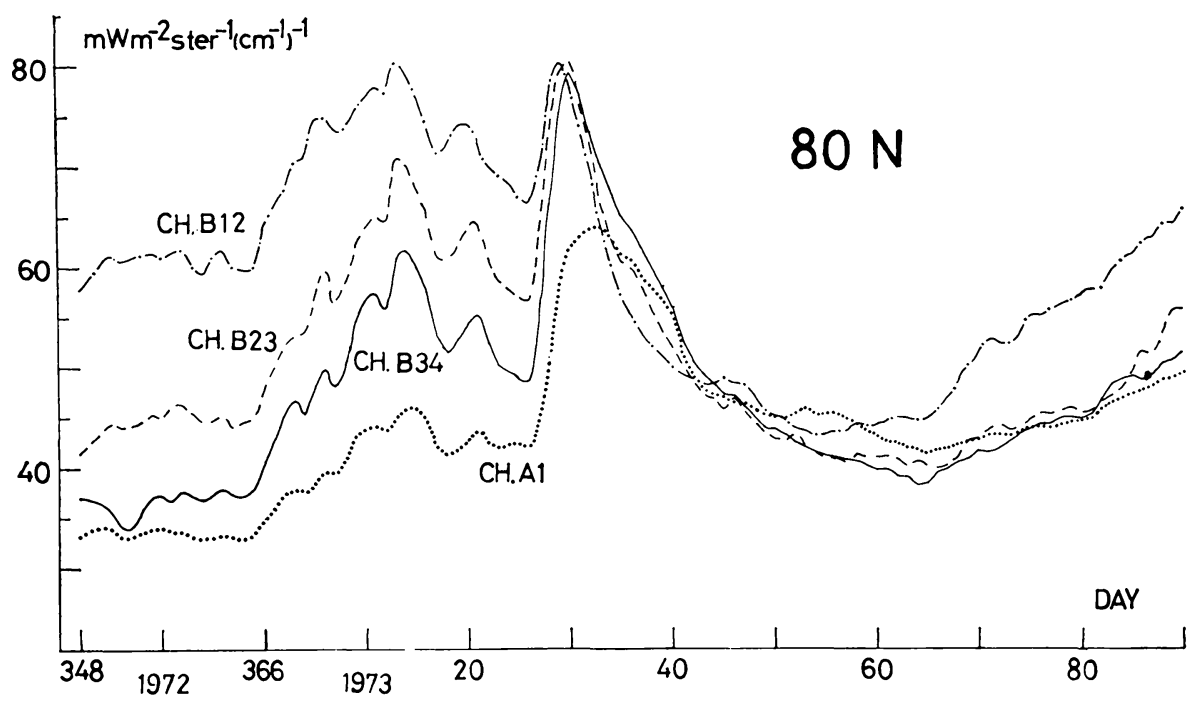

Fig. 2 Time variations of zonal mean radiance at $80^{\circ} \mathrm{N}$ for channels B12, B23, B34 and $\mathrm{A} 1$ (units in $\left.\mathrm{mW} \mathrm{m}-2 \operatorname{ster}^{-1}\left(\mathrm{~cm}^{-1}\right)^{-1}\right)$. 
Table 2. A list of northern hemisphere stratospheric warmings observed by satellites.

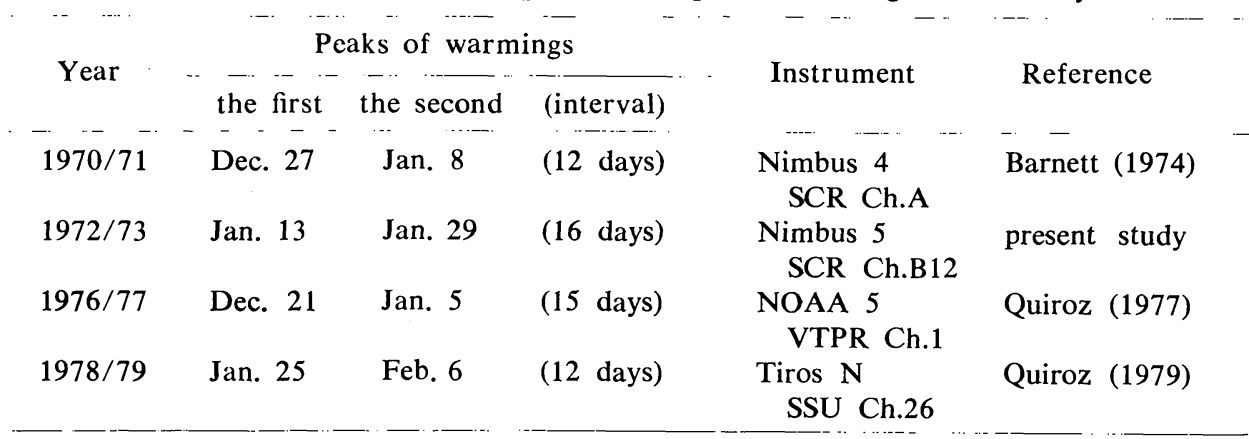

the 1971 major warming observed by the Nimbus 4 SCR channel B whose weighting is similar to that of the Nimbus 5 SCR channel B34 (see Barnett, 1974). The values of the peak of Warming 2 were larger than those of Warming 1, except for the uppermost channel B12. It is indicated that Warming 2 was centered at lower altitudes than Warming 1 in view of the weighting functions. The warming peaks descended rapidly with the peak in channel $A 1$ appearing three days later than that in channel B12.

We may as well consider the two warmings together as an event. An interval of the two peaks was about 16 days. The minimum value of radiance around day 25 became about 10 units larger than the value before about day 366 for each channel. It is speculated that Warming 1 brought about the condition to make the more sudden Warming 2 occur more easily. In section 6 , this point will be discussed again in terms of the effect of mean zonal wind profile on planetary wave amplifications. Examination of the previous observational studies using satellite infrared data for the middle and upper stratospheric temperatures indicate that a major or minor warming always occurs about two weeks before a spectacular major warming and the second warming begins at the higher temperature than the first warming. From this point of view the northern hemispheric major warmings of $1970 / 71,1972 / 73,1976 / 77$ and $1978 / 79$ are summarized in Table 2.

Fig. 3 shows the evolution of latitudinal distribution of zonal mean radiance field of channels B12 and B34, for every 5 days in Warming 1 and every 3 days in Warming 2. As for the meridional radiance (temperature) gradient reversal at the peak of the warmings, it was greatest for the lower channel B34 in Warming 2 and for the upper channel B12 Warming 1 matched Warming 2 in its intensity. When the atmosphere in northern hemisphere higher latitude area became warmer the atmosphere south of a certain latitude became cooler, in agreement with previous satellite observations (e.g. Fritz and Soules, 1970). In Warming 1 the maximum radiance first appeared at middle latitudes and gradually moved poleward for these two channels while in Warming 2 for channel B34 a maximum appeared first at about $60^{\circ} \mathrm{N}$ and for channel $\mathrm{B} 12$ at the pole. These meridional temperature profiles suggest mean zonal wind variations through the thermal wind relation.

\section{Mean zonal wind and planetary-scale disturbances}

We will discuss the behavior of mean zonal wind and planetary-scale disturbances of wavenumber 1,2 and 3 with paying attention to their dynamical interactions in order to understand the 1973 sudden warming. We will lay emphasis on the description of how occurred the casterly flow accompanying the meridional temperature gradient reversal and which wavenumber amplitude of disturbances became large during the casterly accelerations.

\subsection{Time sections}

Fig. 4 shows time-height sections of mean zonal wind at $72^{\circ} \mathrm{N}$ and $52^{\circ} \mathrm{N}$, respectively. At $72^{\circ} \mathrm{N}$ a large easterly area corresponding to Warming 2 appeared first on day 28 in higher levels and moved downward to the $20 \mathrm{~km}$ level. It is noted that around day 25 before the appearance of the easterlies a westerly maximum is observed in the upper stratosphere. After about day 20 wind oscillations above and below about $20 \mathrm{~km}$ seem to be negatively correlated, with the appearance of the tropospheric easterlies. Corresponding to Warming 1 , the easterlies appeared around day 14 in the lower mesosphere, but did not move downward to the lower atmos- 
WARMING 1
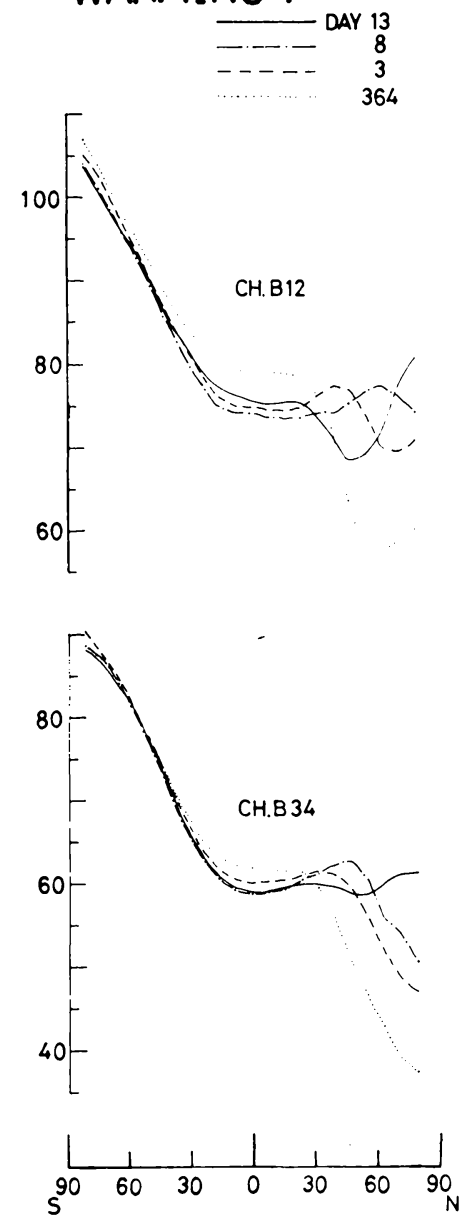

WARMING 2
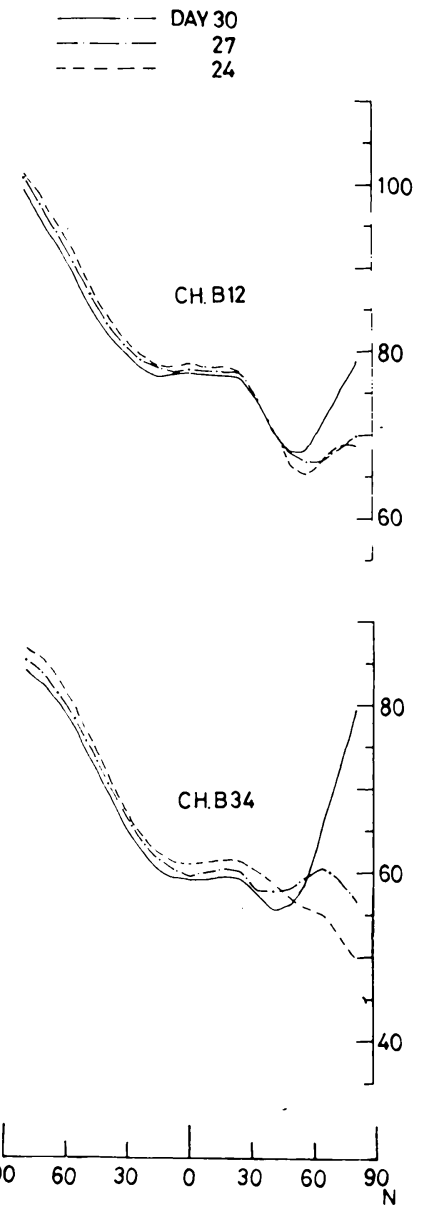

Fig. 3 Evolution of the latitudinal profile of zonal mean radiance for channels B12 and B34, plotted every 5 days in Warming 1 while every 3 days in Warming 2 (units in $\left.\mathrm{mW} \mathrm{m}^{-2} \operatorname{ster}^{-1}\left(\mathrm{~cm}^{-1}\right)^{-1}\right)$.

phere. At $52^{\circ} \mathrm{N}$ the easterlies appeared almost at the same time throughout the upper layer with the first appearance around day 27 and $45 \mathrm{~km}$ level. The easterly wind region as a whole descended but was confined to the upper stratosphere.

Fig. 5 shows time-latitude sections of mean zonal wind and amplitudes of zonal wavenumber 1,2 and 3 geopotential height at $3 \mathrm{mb}$ (ca. 40 $\mathrm{km}$ ) which may be representative of the upper stratosphere. Corresponding to Warming 1, easterly accelerations of mean zonal wind occurred first in middle latitudes around day 8 and then in high latitudes around day 12 , as was expected from the evolution of zonal mean radiance's latitudinal profile (see Fig. 3). In Warming 1 easterlies did not appear at this level.
It is noticeable that around day 27 easterly winds appeared first in middle latitudes where weak westerlies had continued since about day 10 . In high latitudes around day 25 a westerly wind maximum occurred and the westerlies were replaced by the easterlies more suddenly than in middle latitudes. It is worth noting that around day 24 westerly accelerations are observed in high latitudes while easterly accelerations in middle latitudes. After the easterlies appeared the westerlies became strong in lower latitudes. The characteristics of the mean zonal wind variation stated above can be also seen in Crane (1979)'s Fig. 15 (at $2 \mathrm{mb}$ ). During the intense easterly accelerations around day 28 wavenumber 1 amplitude became maximum. Sudden amplification from day 25 (60 dam) to day 28 (140 dam) 


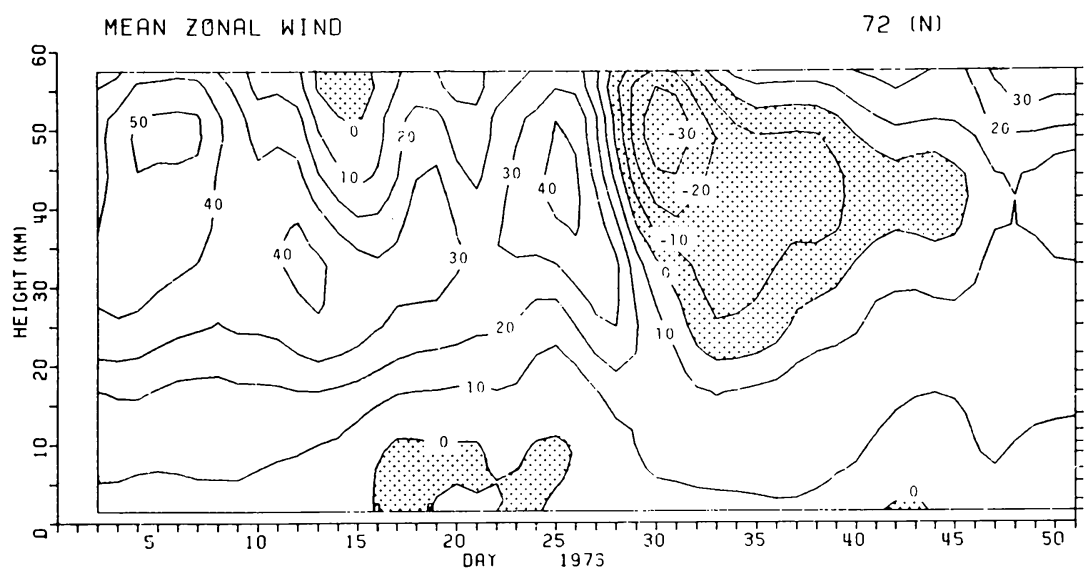

(a)

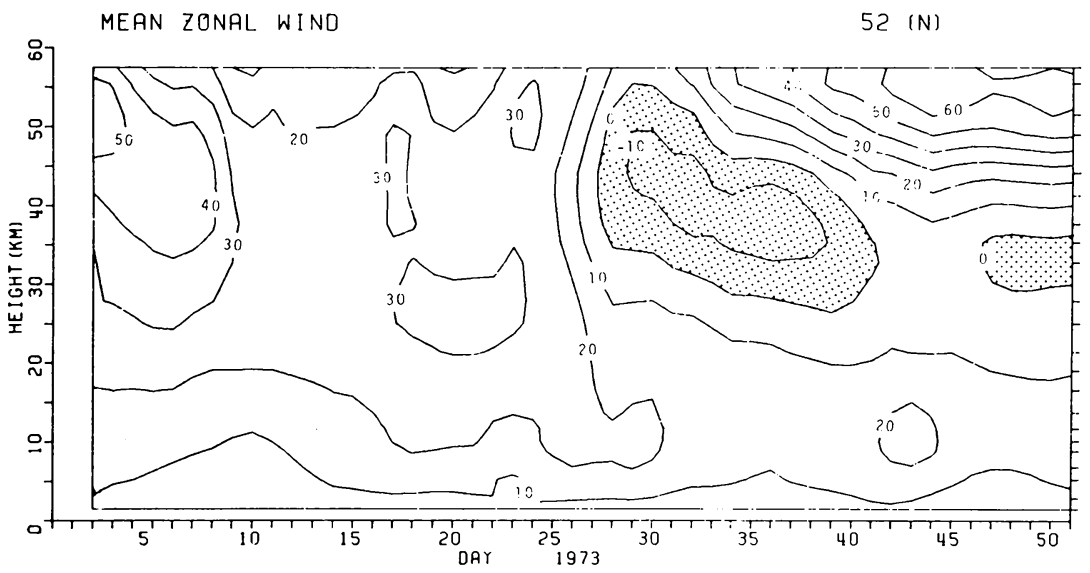

(b)

Fig. 4 Time-height sections of mean zonal wind $\left(\mathrm{m} \mathrm{s}^{-1}\right)$ at $72^{\circ} \mathrm{N}$ (a) and $52^{\circ} \mathrm{N}$ (b). Easterly winds are stippled. The right side ordinate gives the levels where the data are available ( 22 levels). The left side ordinate gives standard heights.

is remarkable. We can deduce that the wavenumber 1 amplification played a most important role in bringing about the circulation reversal of the polar stratosphere in Warming 2. Around day 24 and $50^{\circ} \mathrm{N}$ where the easterly accelerations occurred first, wavenumber 2 (50 dam) surpasses wavenumber 1 ( $20 \mathrm{dam})$ in amplitude. This may indicate that the role of wavenumber 2 was important in the zonal wind deceleration in its first stage. This will be discussed again in section 5 . The alternating amplification of wavenumber 1 and 2 disturbances during the easterly accelerations is also found in Warming 1 when the amplification of wavenumber 1 was weaker. Wavenumber 2 amplitude became slightly smaller around day 28 and maximum (70 dam) near $56^{\circ} \mathrm{N}$ on day 30 during the wavenumber 1 decay stage in the easterly wind region. And then wavenumber 3 had maximum amplitude (35 dam) near $44^{\circ} \mathrm{N}$ on day 33 . Thus the amplitude maxima have a tendency to move toward lower latitudes, that is to say, toward the westerly wind region. The disturbances of zonal wavenumbers higher than 3 had small amplitude and then are not shown here. Generally the maximum amplitudes of wavenumber 1 take up its position higher in latitude than that of wavenumber 2 .

Fig. 6 shows time-height sections of amplitudes of zonal wavenumber 1 and 2 geopotential height at $60^{\circ} \mathrm{N}$ and wavenumber 3 at $48^{\circ} \mathrm{N}$. On day 28 when the intense easterly accelerations of the mean zonal flow occurred, wavenumber 1 

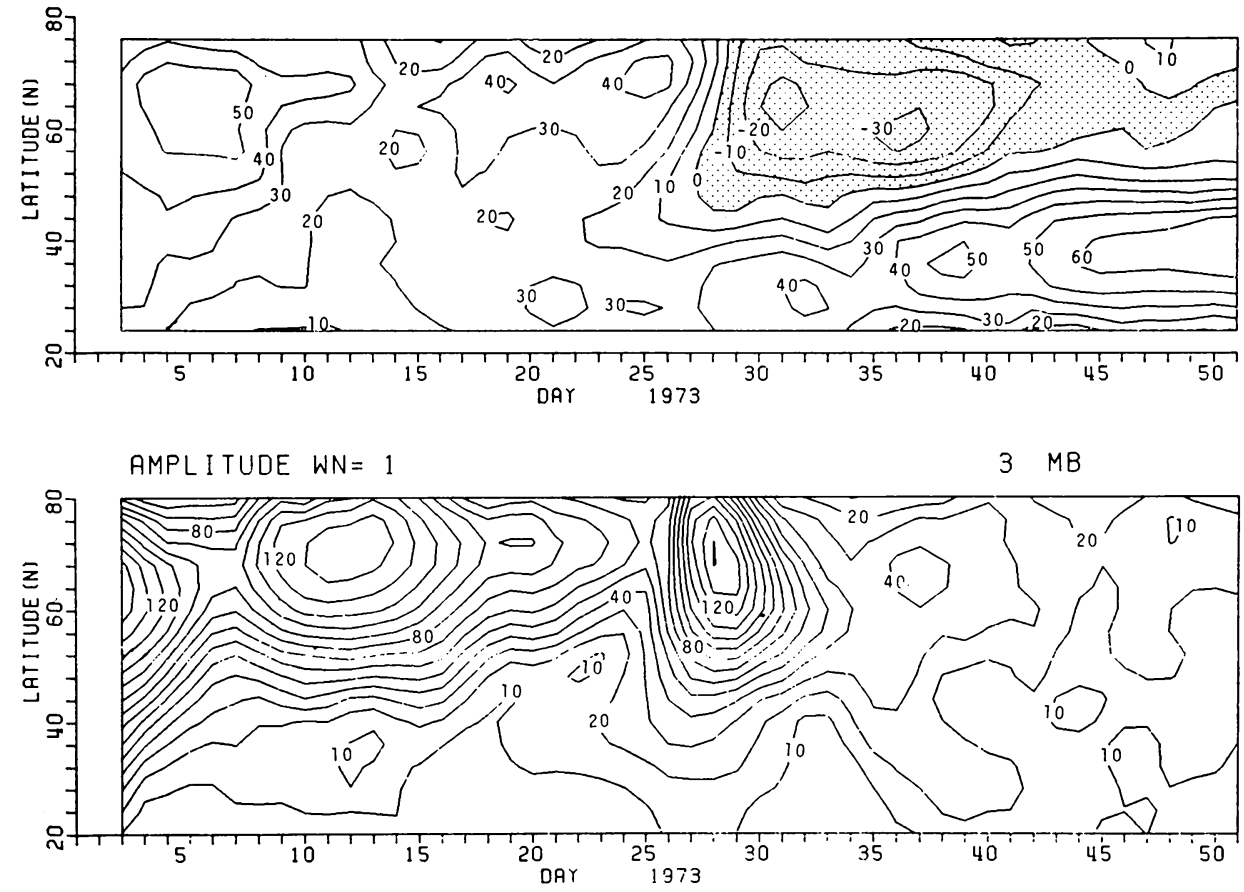

(b)

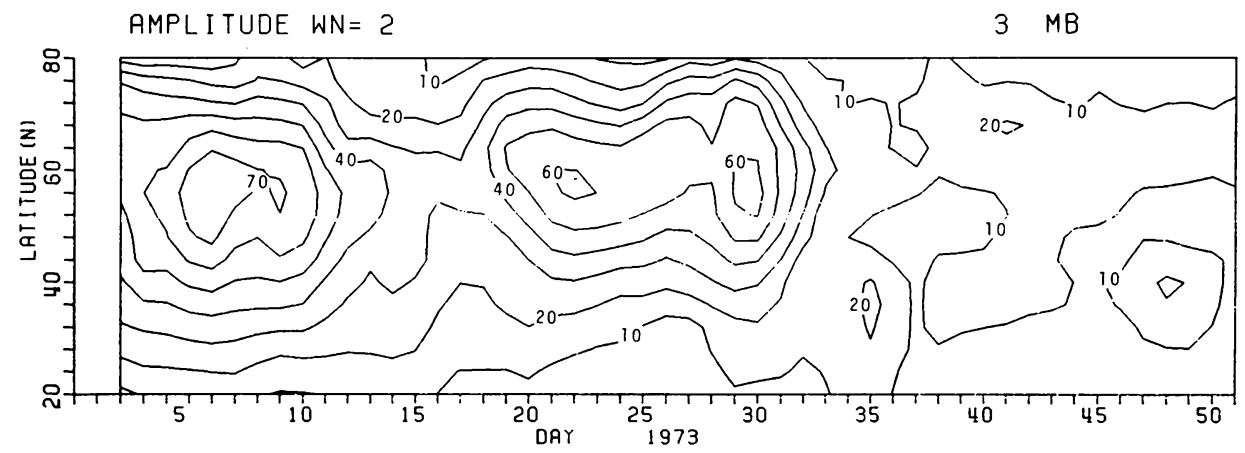

(c)

AMPLITUDE WN=3

$3 \mathrm{MB}$

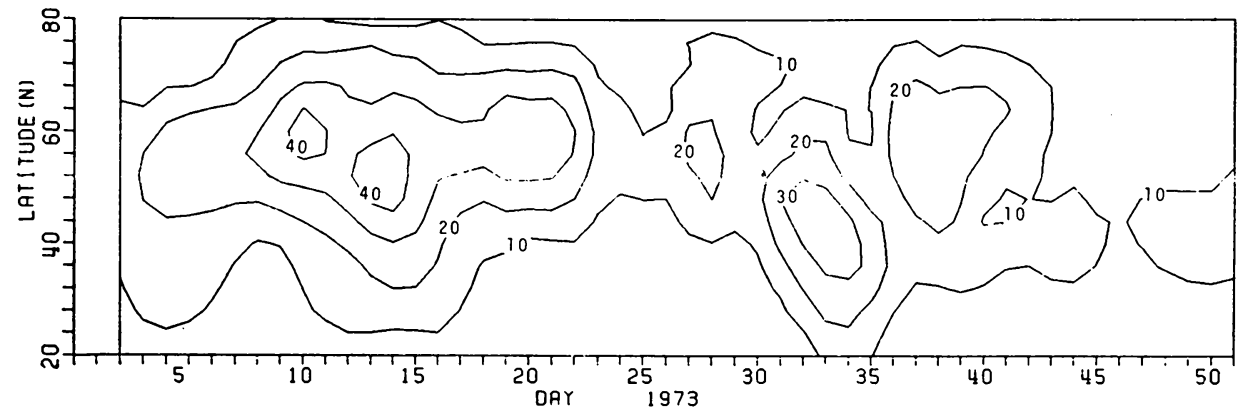

Fig. 5 Time-latitude sections of mean zonal wind (a), geopotential height amplitude of wavenumber 1(b), wavenumber 2(c) and wavenumber $3(\mathrm{~d})$ at $3 \mathrm{mb}$. Easterly winds are stippled. Contour lines are drawn with $10 \mathrm{~m} \mathrm{~s}^{-1}$ interval for wind and 10 decameter interval for amplitudes. 


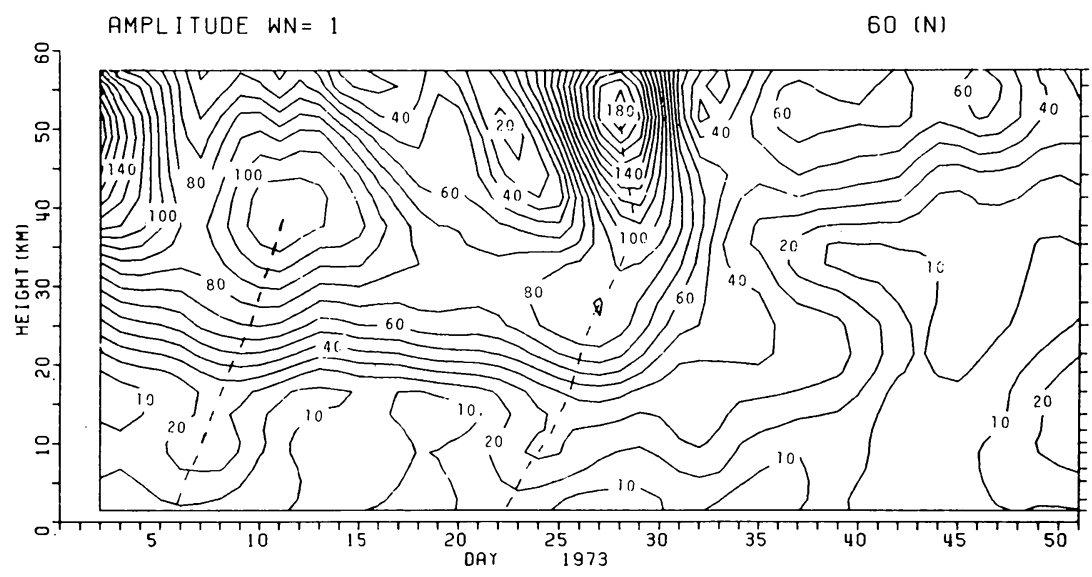

(a)

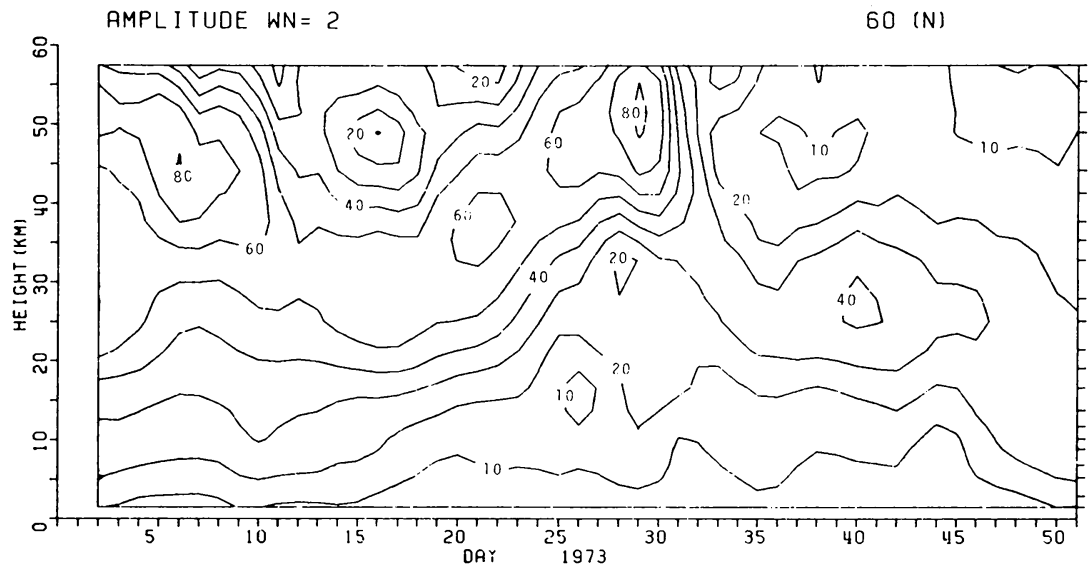

(b)

AMPLITUDE $W N=3$

$48(N)$

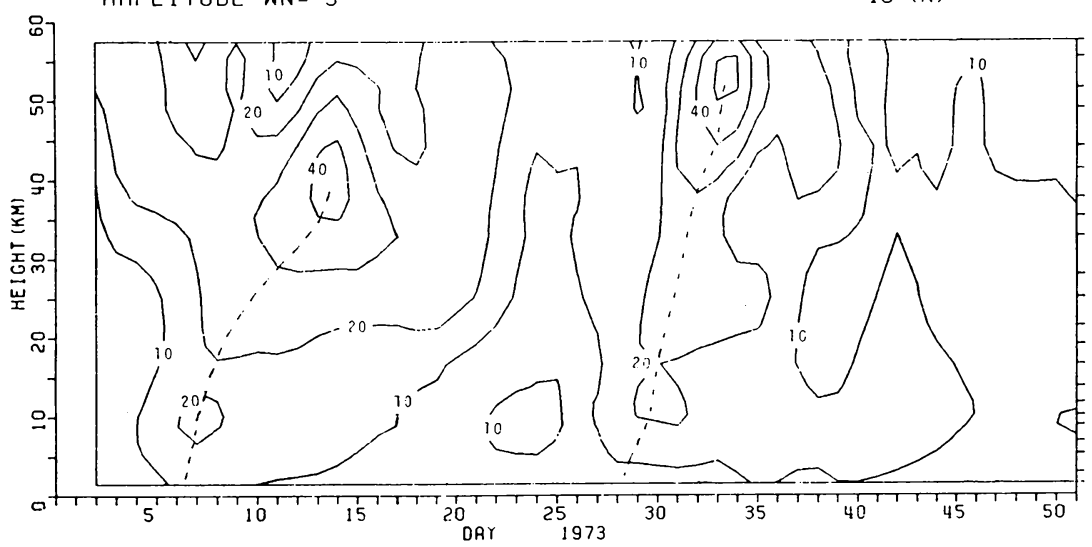

(c)

Fig. 6 Time-height sections of geopotential height amplitude of wavenumber 1 at $60^{\circ} \mathrm{N}$ (a), wavenumber 2 at $60^{\circ} \mathrm{N}$ (b) and wavenumber 3 at $48^{\circ} \mathrm{N}$ (c). Contour lines are drawn with 10 decameter interval. 
amplitude reached its maximum value of 180 decameters at the stratopause level (ca. $50 \mathrm{~km}$ ). The amplitude maximum appeared simultaneously in height above about $40 \mathrm{~km}$ with a weak tendency to move downward. Below this level a ridge line (see the dotted line in Fig. 6(a)) continues down to the tropospheric lower levels with the maximum amplitude in lower levels preceding that in higher levels, which may indicate that the wavenumber 1 disturbances was propagating from below. Roughly estimated vertical propagation speed is about $6 \mathrm{~km}$ per day. This upward propagation is also found in the middle latitude region from $44^{\circ} \mathrm{N}$ to $64^{\circ} \mathrm{N}$. Crane (1979) concluded that for the $50-0.4 \mathrm{mb}$ region during Warming 2 there was no indication of upward propagation of wavenumber 1 . But by the extension of the analysis region to the troposphere in the present study, the upward propagation of wavenumber 1 is indicated below about $40 \mathrm{~km}$ level, as also seen in Muench (1965), Hirota and Sato (1969), Iwashima (1973) and Quiroz (1979) who used the radiosonde data below $10 \mathrm{mb}$ (ca. $30 \mathrm{~km}$ ). During Warming 1 the upward propagation of wavenumber 1 is also indicated, but above about $40 \mathrm{~km}$ level the strong amplification is not observed. As for wavenumber 2 there is no indication of upward propagation, as also reported by the above authors. The vertical propagation of wavenumber 3 is found in lower latitudes and about a few days later than that of wavenumber 1 (see the dotted lines in Fig. 6(c)). In the troposphere the maximum values of wavenumber 1,2 and 3 were almost the same one another, for example, about 20 decameters at $500 \mathrm{mb}$. However in the stratosphere the amplitude of the disturbances is observed to increase with decreasing wavenumber, as also stated in the previous studies using the data below $10 \mathrm{mb}$. This fact may be basically accounted for in terms of the theory of vertical propagation of stationary planetary waves (e.g. Charney and Drazin, 1961).

Fig. 7 shows time-height sections of phase angle of wavenumber 1 and 2 geopotential height at $60^{\circ} \mathrm{N}$ and wavenumber 3 at $48^{\circ} \mathrm{N}$. Generally for wavenumber 1 phase we can see quasistationarity and westward tilts with increasing height which brings about positive poleward eddy heat flux, as was also stated by many authors. During Warming 2 are observed strong westward tilts with height which were realized by westward progressions in the upper stratosphere. Wavenumber 2 phase tilts were weak and phase progressions were large compared with that of wave- number 1. The phase progressed eastward from about day 10 to day 25 when the weak amplification of wavenumber 2 occurred in the stratosphere (see Fig. 6(b)). The relation between eastward phase progression and amplification for wavenumber 2 was reported by Leovy and Webster (1976) in terms of thickness derived from Nimbus 4 SCR data. Wavenumber 3 phase progressions were also large. During the two amplification period (see Fig. 6(c)), we can see castward phase progressions with conserving westward tilts with height in the stratosphere.

\subsection{Meridional cross-sections}

a) Mean zonal wind

Fig. 8 shows meridional cross-sections of mean zonal wind on day $2,7,10$ and 13 . The mean zonal wind structure on day 2 would be near in its general features to that of normal winter based on conventional radiosonde and rocketsonde data, for example, by Murgatroyd (1969). The differences between the wind on day 2 and of Murgatroyd's Fig. 1(b) may be that the upper atmospheric westerly maximum on day 2 situated around $56^{\circ} \mathrm{N}$ and $50 \mathrm{~km}$ takes a position north of and below that of normal winter $\left(45^{\circ} \mathrm{N}, 65\right.$ $\mathrm{km})$. On day 7 , the stratospheric westerly jet had shifted poleward to about $68^{\circ} \mathrm{N}$ and in the troposphere double jet was formed. On day 10 , a wind minimum region appeared in the middle latitude upper levels. On day 13, a westerly maximum in high latitudes descended to the 30 $\mathrm{km}$ level while another westerly jet appeared in the low latitude upper levels and easterlies appeared in the high latitude upper levels. Thus corresponding to Warming 1 , the mean zonal wind profile had been changed very much, though the stratospheric polar westerly jet was not replaced by easterly flows. By the appearance of the weak westerly wind in the middle latitude upper stratosphere, the polar westerly jet had maximum near $30 \mathrm{~km}$ so that the area in easterly shear with increasing height and decreasing latitude emerged in the higher latitude upper stratosphere and the polar jet was cut off from a strong westerly wind in the lower latitude lower mesosphere.

Fig. 9 shows meridional cross-sections of mean zonal wind on day 19,22, 25, 28, 31 and 34 during Warming 2 . The wind distributions common through pre-warming period (day 19, 22 and 25) shows that a maximum westerly wind region is situated around $70^{\circ} \mathrm{N}$ and $40 \mathrm{~km}$ and is cut off from another westerly jet near $60 \mathrm{~km}$ 


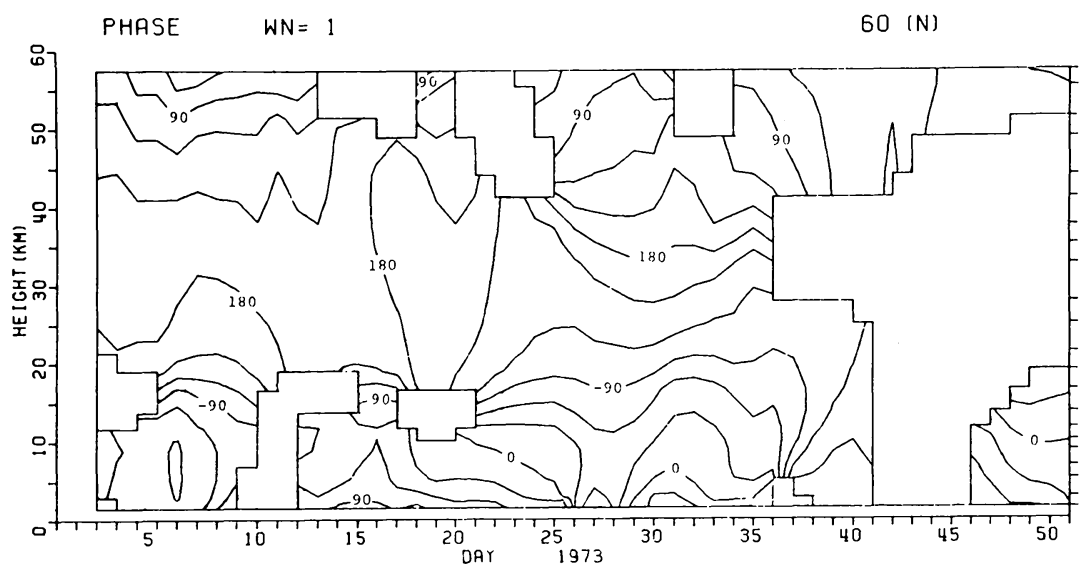

(a)

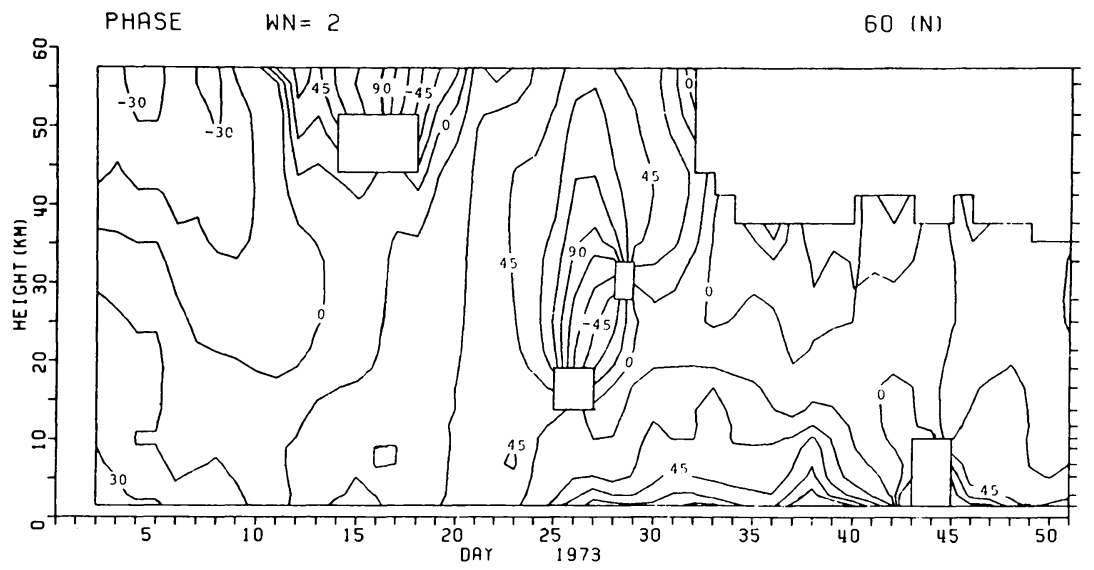

(b)

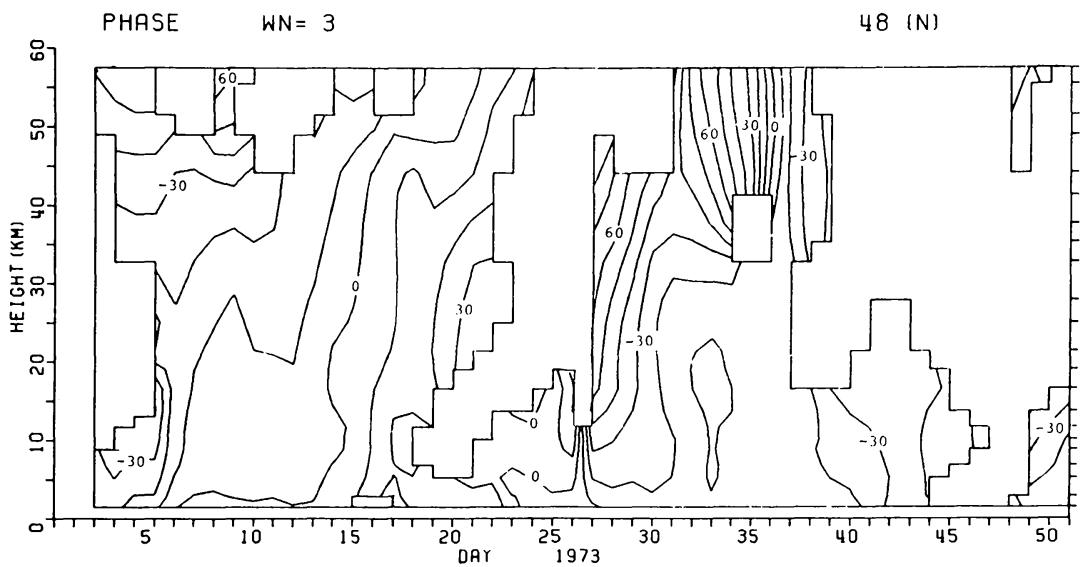

(c)

Fig. 7 Time-height sections of geopotential height phase angle of ridge for wavenumber 1 at $60^{\circ} \mathrm{N}$, wavenumber 2 at $60^{\circ} \mathrm{N}$ (b) and wavenumber 3 at $48^{\circ} \mathrm{N}$ (c). Positive values denote east longitudes with one wavelength equalling $360^{\circ}$ divided by wavenumber. Contour lines are drawn with $\pi / 6$ interval. Phases are not drawn for amplitudes smaller than 20 percent of the maximum amplitude at each level. 


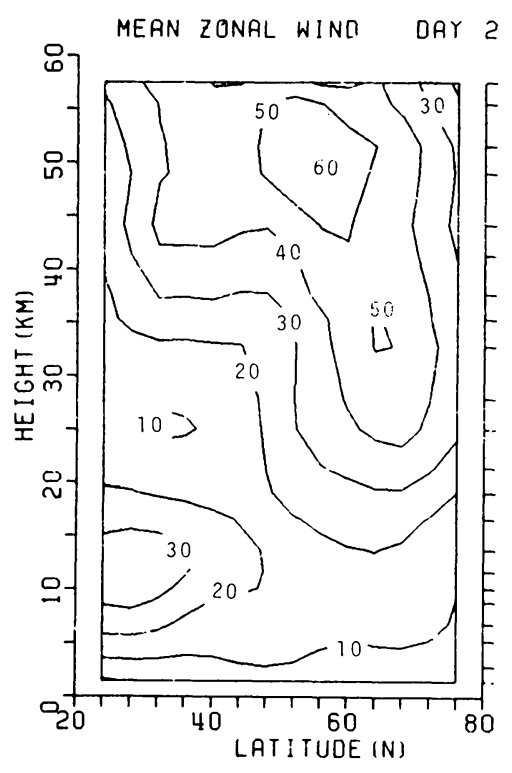

(a)

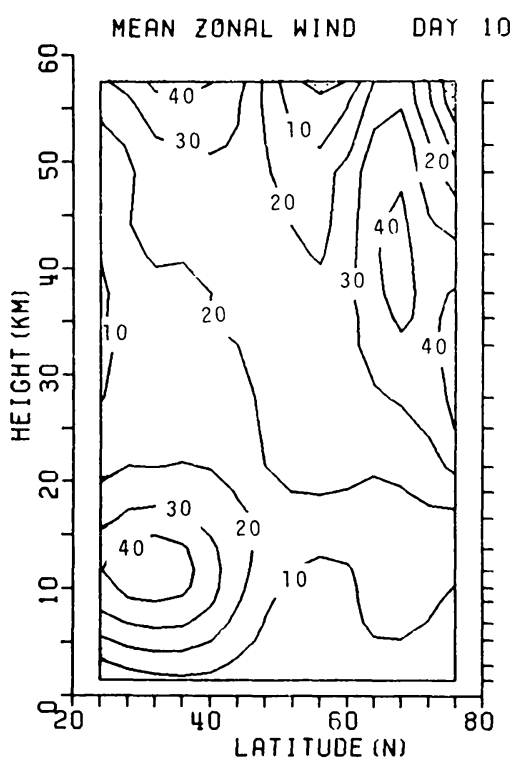

(c)

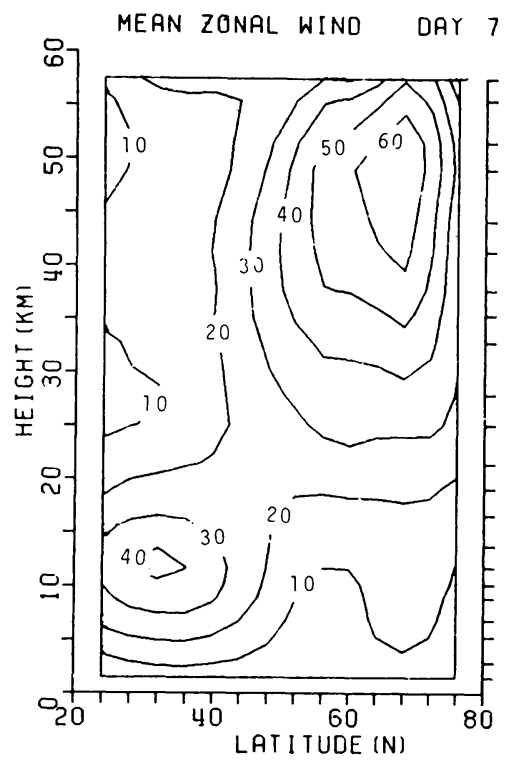

(b)

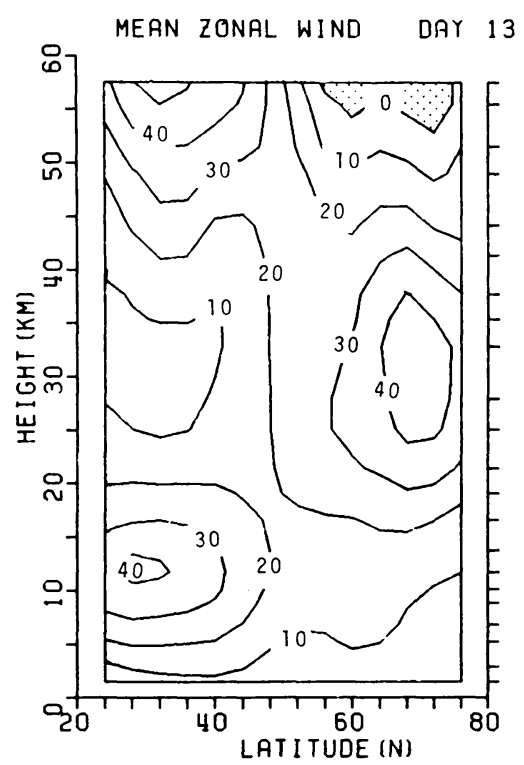

(d)

Fig. 8 Latitude-height sections of mean zonal wind $\left(\mathrm{m} \mathrm{s}^{-1}\right)$ on day 2(a), day 7(b), day 10 (c) and day 13(d). Easterly winds are stippled. The right side ordinate gives the levels where the data are available (22 levels).

in lower latitudes by a wind minimum region. These characteristics are almost common to those on day 13. In this sense the effect of Warming 1 on the mean zonal wind profile continued to remain through about 10 days. On day 28, a region of easterly flow appeared. The easterly region agrees approximately with the wind mini- mum region in the middle latitude upper stratosphere during pre-warming period. A westerly maximum in high latitudes descended to about $30 \mathrm{~km}$ level. On day 31 , a large area of easterly flow including the polar upper stratosphere was formed with increasing its intensity $\left(-50 \mathrm{~m} \mathrm{~s}^{-1}\right.$ at $\left.65^{\circ} \mathrm{N}, 50 \mathrm{~km}\right)$ and the westerly polar jet dis- 
appeared. On day 34, the easterly region as a on day 2 (see Fig. 8(a)). A tropospheric ampliwhole descended with its base close to the $20 \mathrm{~km}$ tude maximum $\left(17 \mathrm{dam}\right.$ at $\left.48^{\circ} \mathrm{N}, 10 \mathrm{~km}\right)$ is level.

b) Wavenumber 1 geopotential height disturbances

situated north of a tropospheric westerly jet. In

Fig. 10 shows meridional cross-sections of wavenumber 1 height amplitude and phase on day 3, 9 and 15. The amplitude structure on day 3 will be compared with the mean zonal wind the stratosphere a maximum amplitude takes a position close to or slightly north of the axis of the westerly jet. These relations between a mean zonal wind profile and a wavenumber 1 amplitude structure in the meridional plane are similar to the structure of stationary planetary waves in

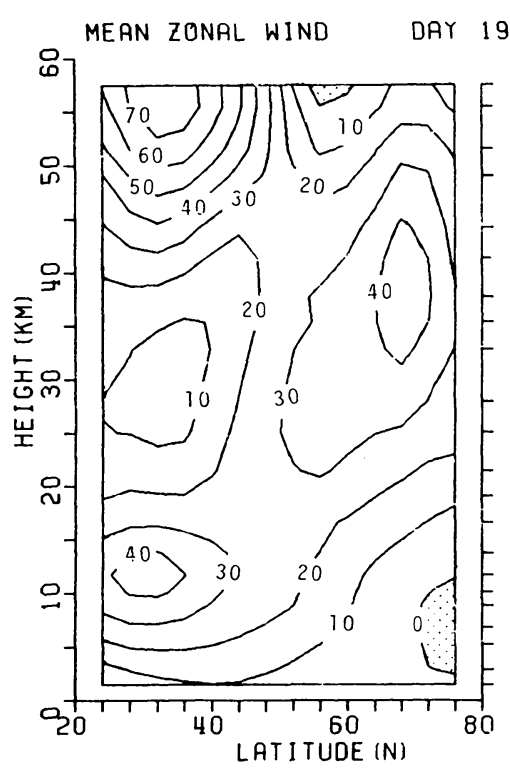

(a)

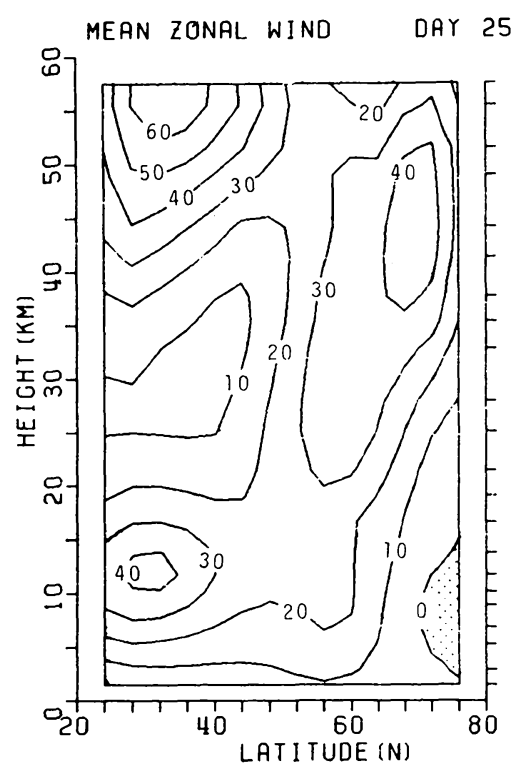

(c)

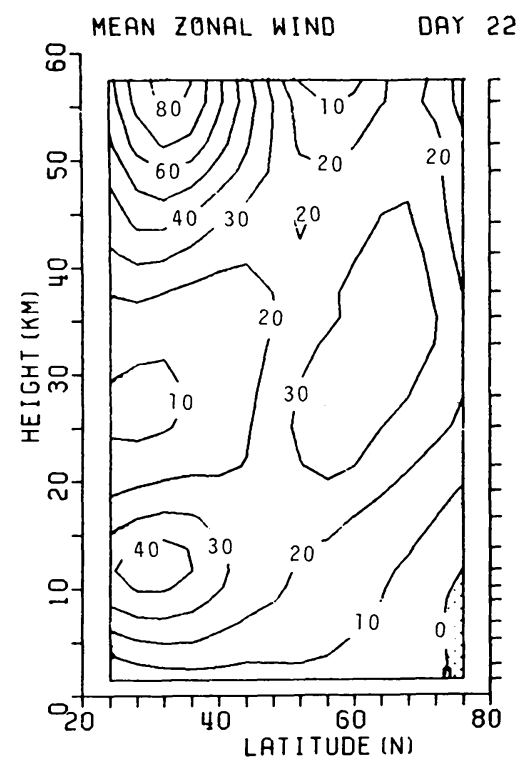

(b)

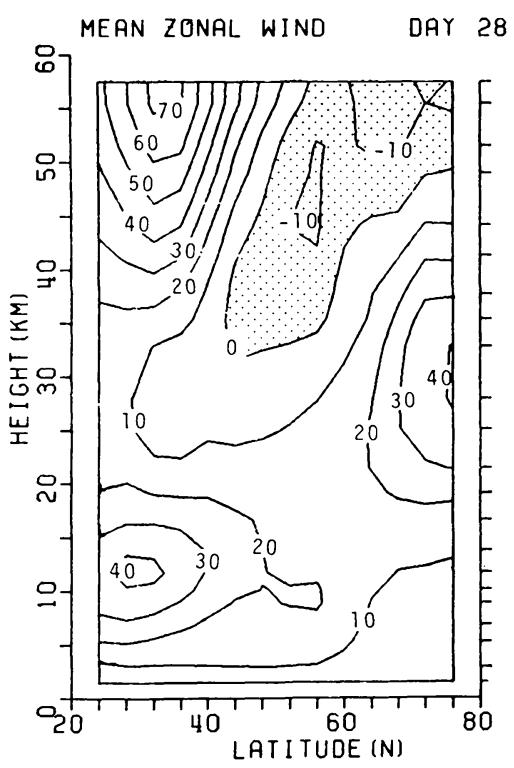

(d)

Fig. 9 


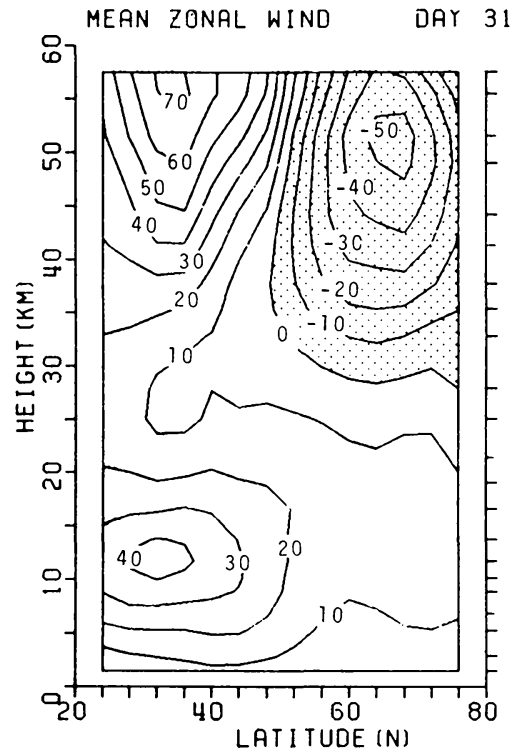

(e)

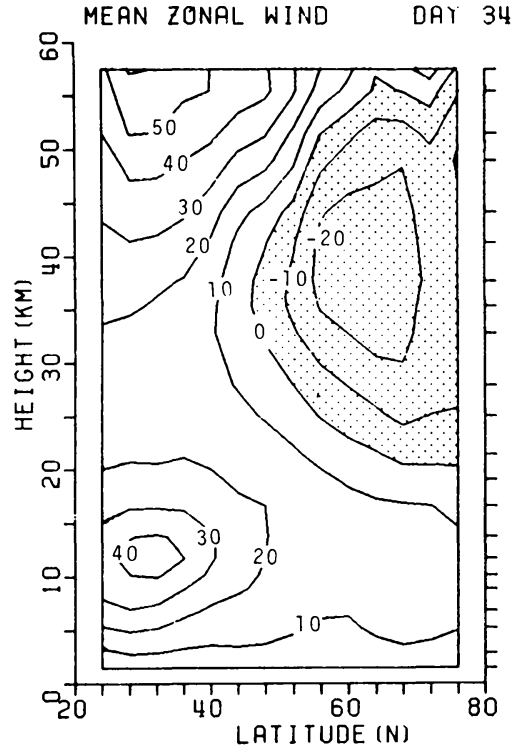

(f)

Fig. 9 As in Fig. 8 but for on day 19(a), day 22(b), day 25(c), day 28(d), day 31(e) and day $34(\mathrm{f})$.

a given mean wind profile investigated by increasing height and decreasing latitude. For Matsuno (1970), Schoeberl, Geller and Avery quasi-geostrophic disturbances which we are now (1979) and Simmons (1978). In the upper strato- treating, this phase structure means a positive sphere and the lower latitude lower stratosphere poleward eddy flux of heat and zonal momentum, and troposphere, we can see westward tilts with accompanied by upward and equatorward trans-
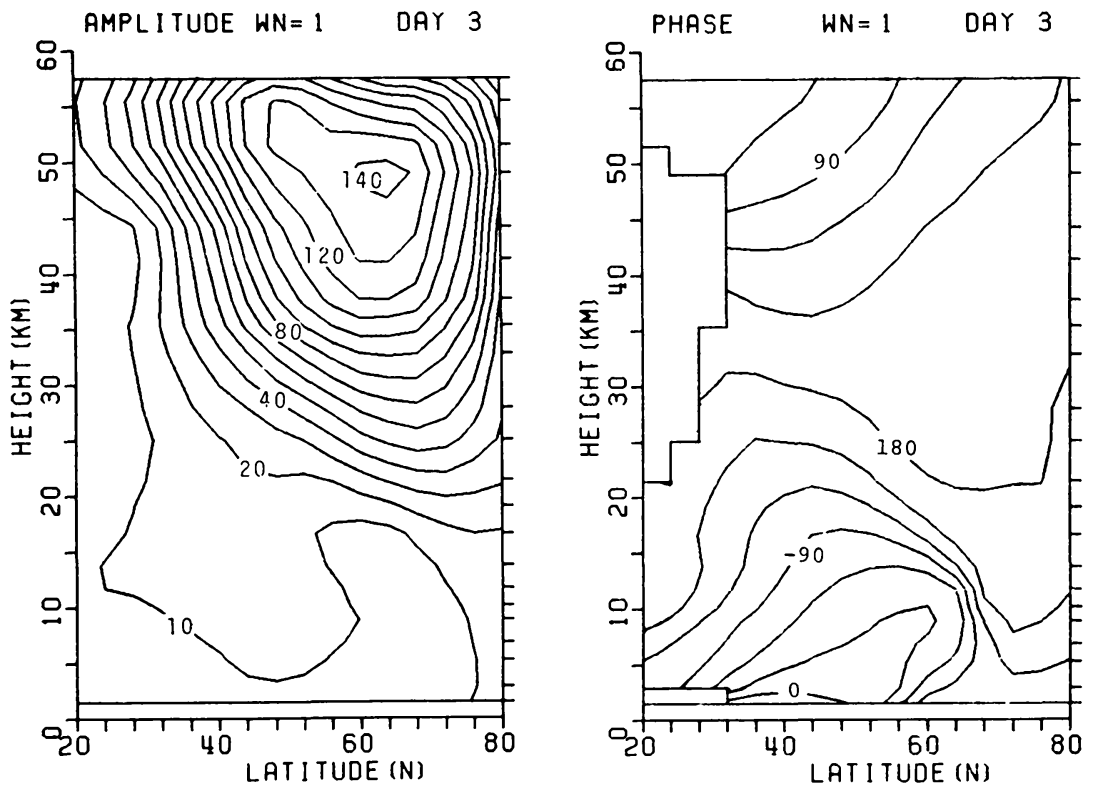

(a)

Fig. 10 
port of energy by the disturbances, respectively, maximum shifted poleward both in the tropoif the mean flow is westerly (Eliassen and Palm, sphere and stratosphere and the meridional 1960). Although we are now treating the transient structure became narrower. This tendency may behavior, Eliassen-Palm relation is considered to coincide with that of mean zonal wind profile be applicable when the mean winds and disturb- variation through these days (see Fig. 8). The ances vary slowly. On day 9, the amplitude phase of wavenumber 1 on day 9 shows the
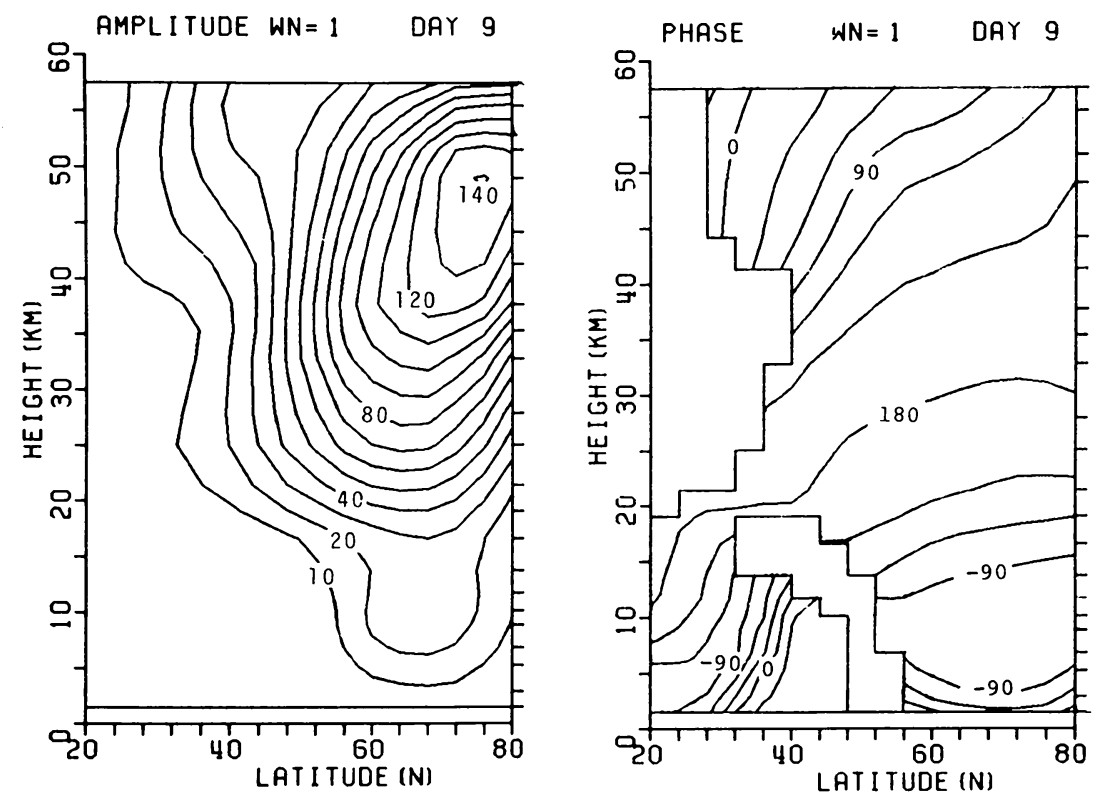

(b)
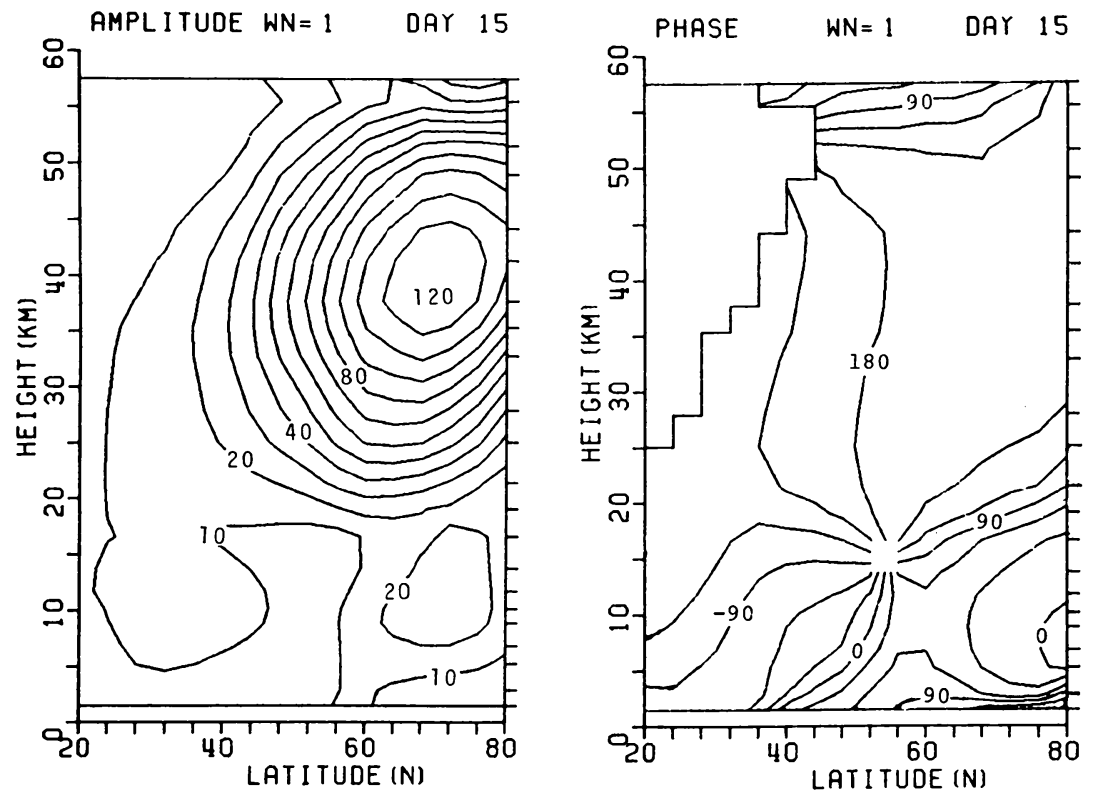

(c)

Fig. 10 Latitude-height sections of wavenumber 1 geopotential height amplitude and phase on day 3(a), day 9(b) and day 15(c). Phases are not drawn for amplitudes smaller than 10 percent of the maximum amplitude at each level. 
eastward tilts with increasing height up to $10 \mathrm{~km}$ in high latitudes and above the level the westward tilts with height in high latitudes had become strong since day 3 . On day 15 when the wavenumber 1 was decaying in its intensity after Warming 1, it had double maximum of amplitude in the troposphere and little phase tilts with height in the upper stratosphere and eastward tilts with height in the high latitude lower stratosphere.

Fig. 11 shows meridional structure of wavenumber 1 on day $22,25,28$ and 31 . On day 22 , a maximum amplitude region in the tropospheric middle and high latitudes was separated from a stratospheric maximum near $30 \mathrm{~km}$ by a node like minimum near $15 \mathrm{~km}$. On day 25 , the tropospheric maximum seems to have propagated up-
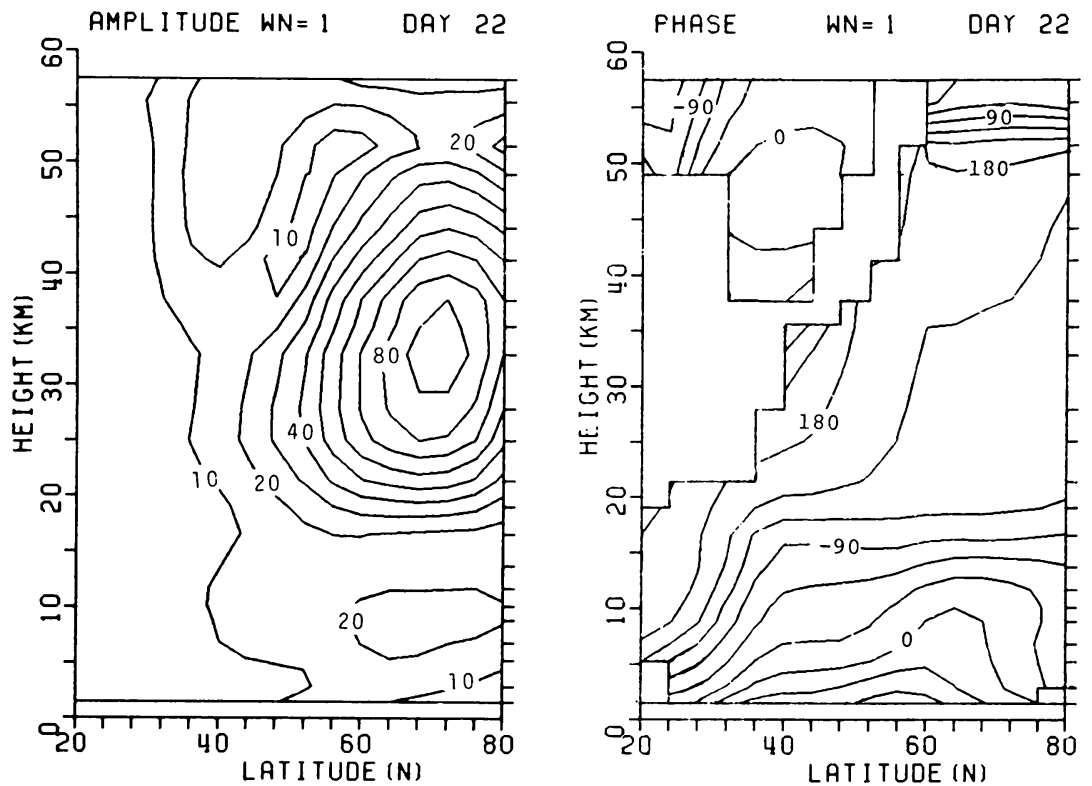

(a)
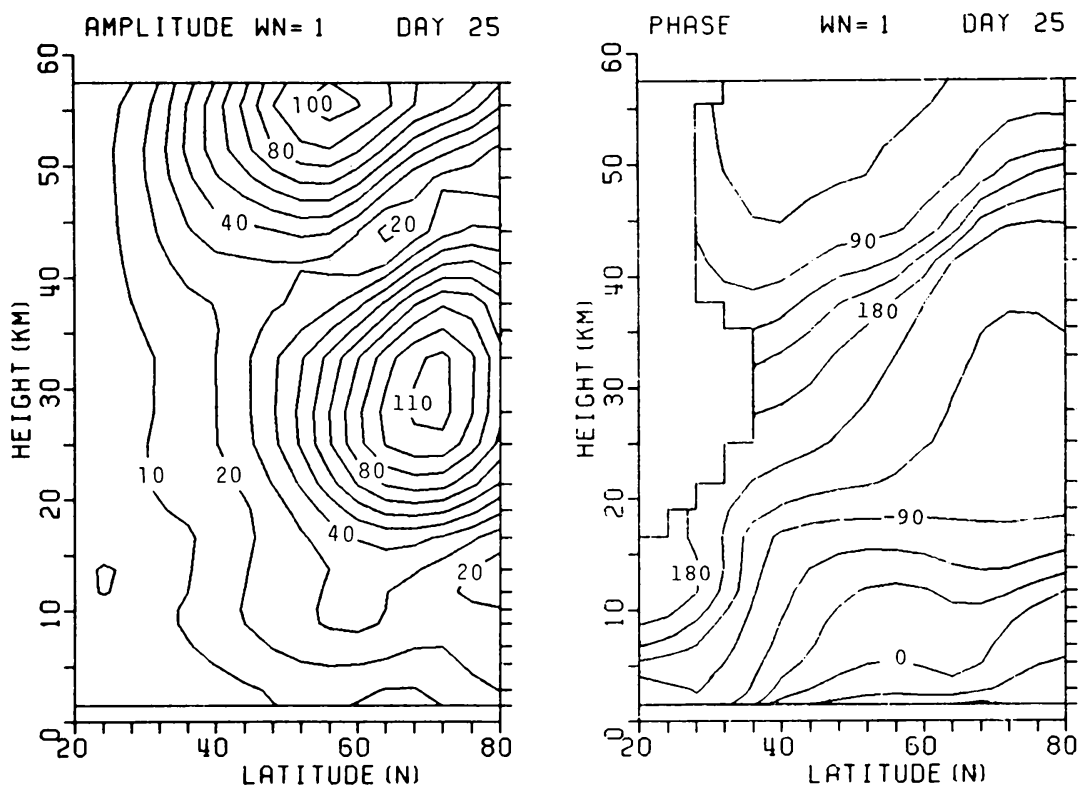

(b)

Fig. 11 
ward and been combined with the stratospheric tween the two amplitude maxima agrees approximaximum which then became strong in magni- mately with the mean zonal wind minimum tude. Thus the upward propagation stated in region on day 19 and 22 (see Fig. 9). The two referring to Fig. 6(a) has been confirmed again. maxima of amplitude on day 25 seem to form And another amplitude maximum appeared in the a maximum amplitude on day 28 at the high lower mesosphere. It is interesting to note that latitude stratopause level with its large value of a node region observed around $40-50 \mathrm{~km}$ be- 220 decameters. Three days later, on day 31 , the
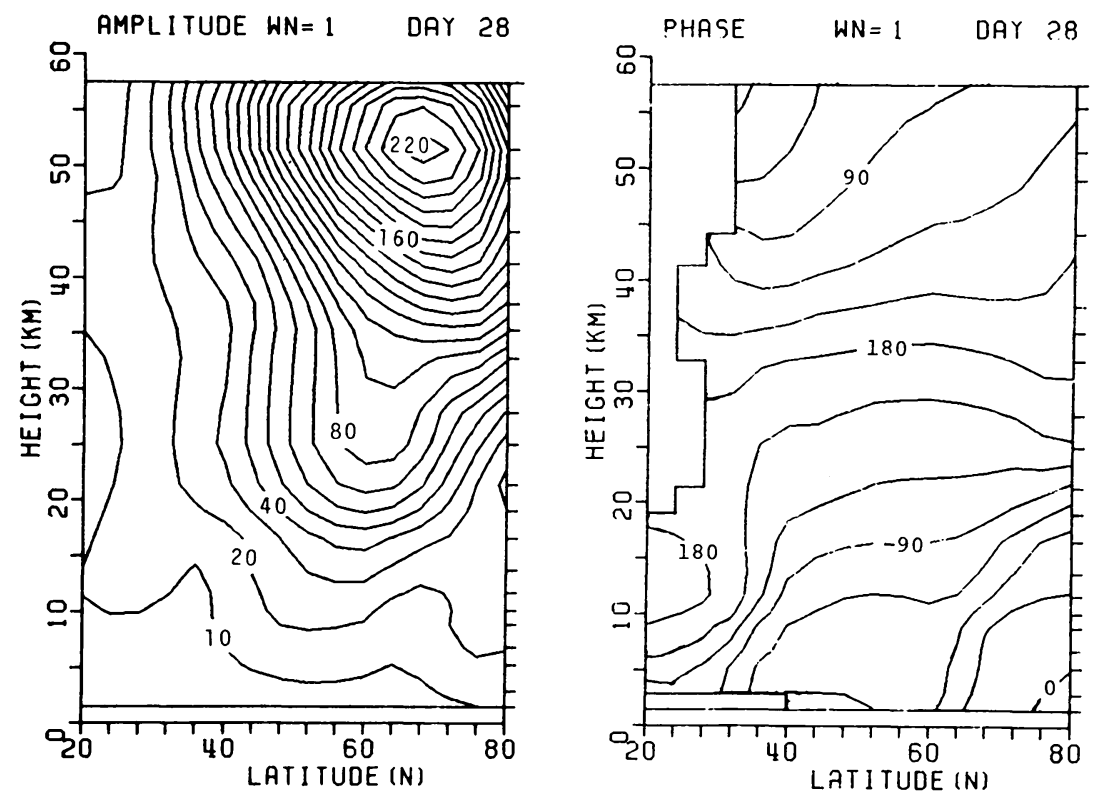

(c)
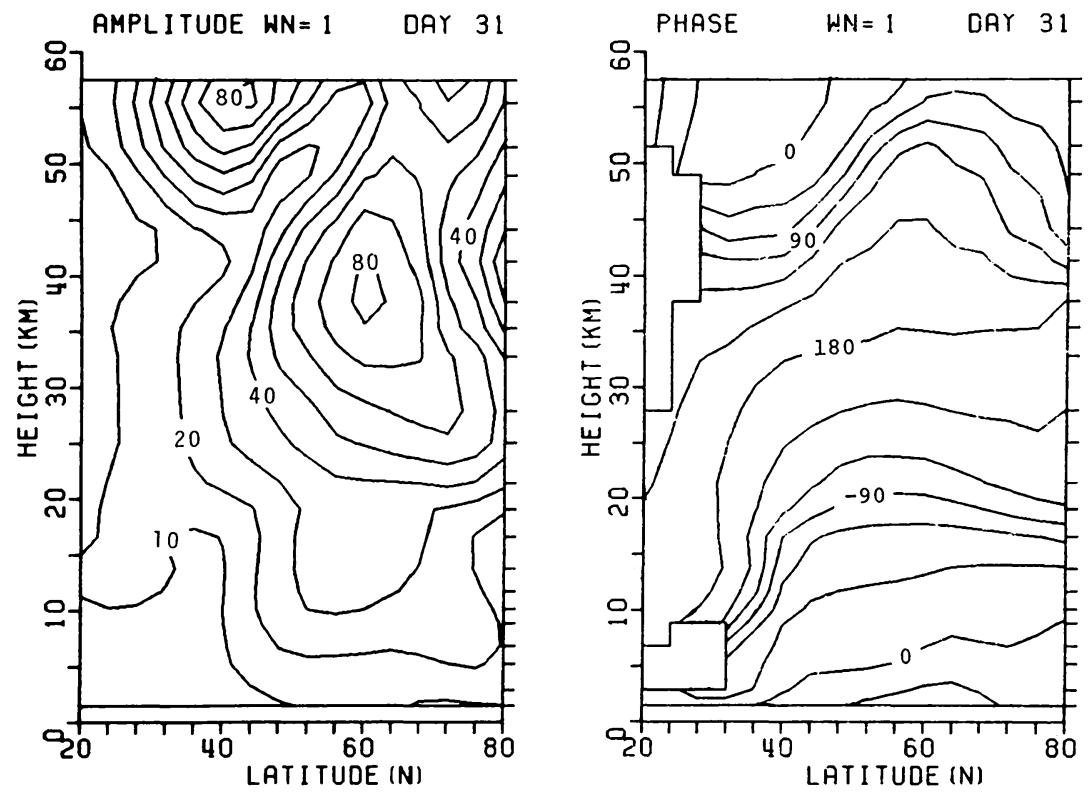

(d)

Fig. 11 As in Fig. 10 but for wavenumber 1 on day 22(a), day 25(b), day 28(c) and day $31(d)$. 
intensity of wavenumber 1 became weak with a the stratospheric high latitudes they became minimum amplitude at the middle latitude stratopause level. As for the phase of wavenumber 1 through these days, we can find the similar characteristics that generally in the meridional plane the phase tilts westward with increasing height and decreasing latitude. In the tropospheric middle latitudes the westward tilts with height became weak from day 25 to day 28 while in strong. It is worth noting that on day 28 when the intense easterly acceleration occurred and the wavenumber 1 amplitude was largest through the period analyzed, the phase gradient directed almost upward which may bring about large poleward heat transport.

c) Wavenumber 2 and 3

Fig. 12 shows meridional structure of wave-
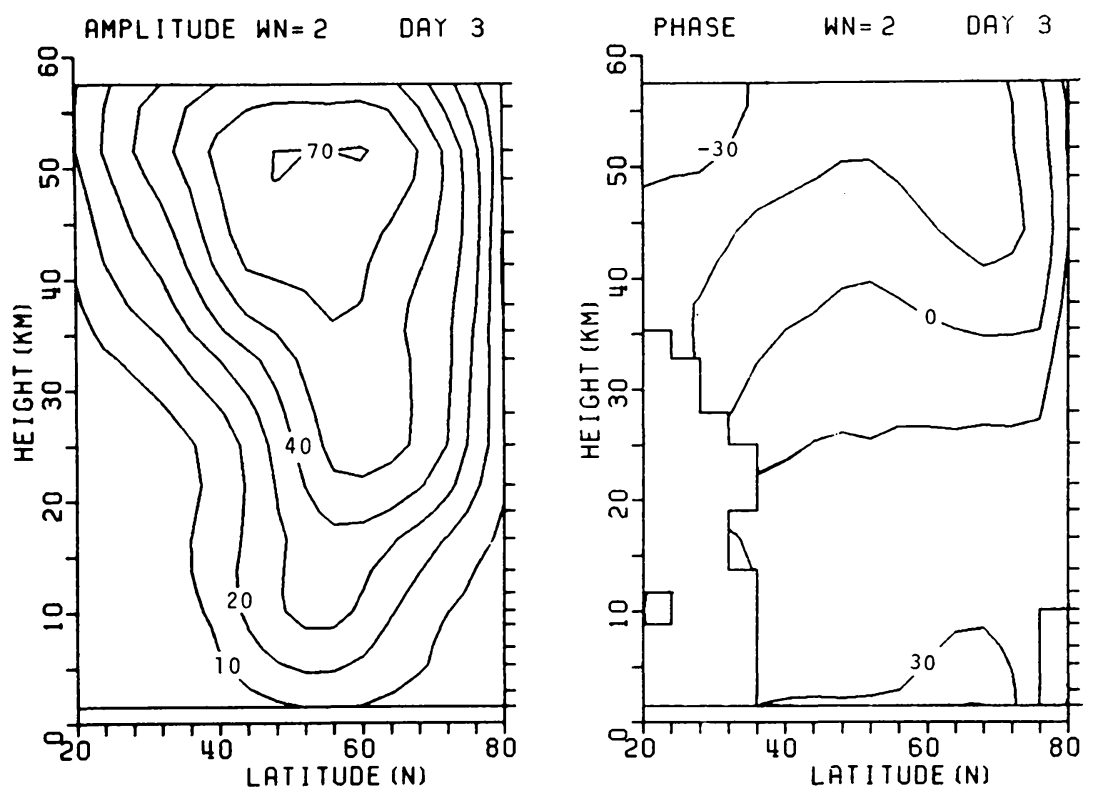

(a)
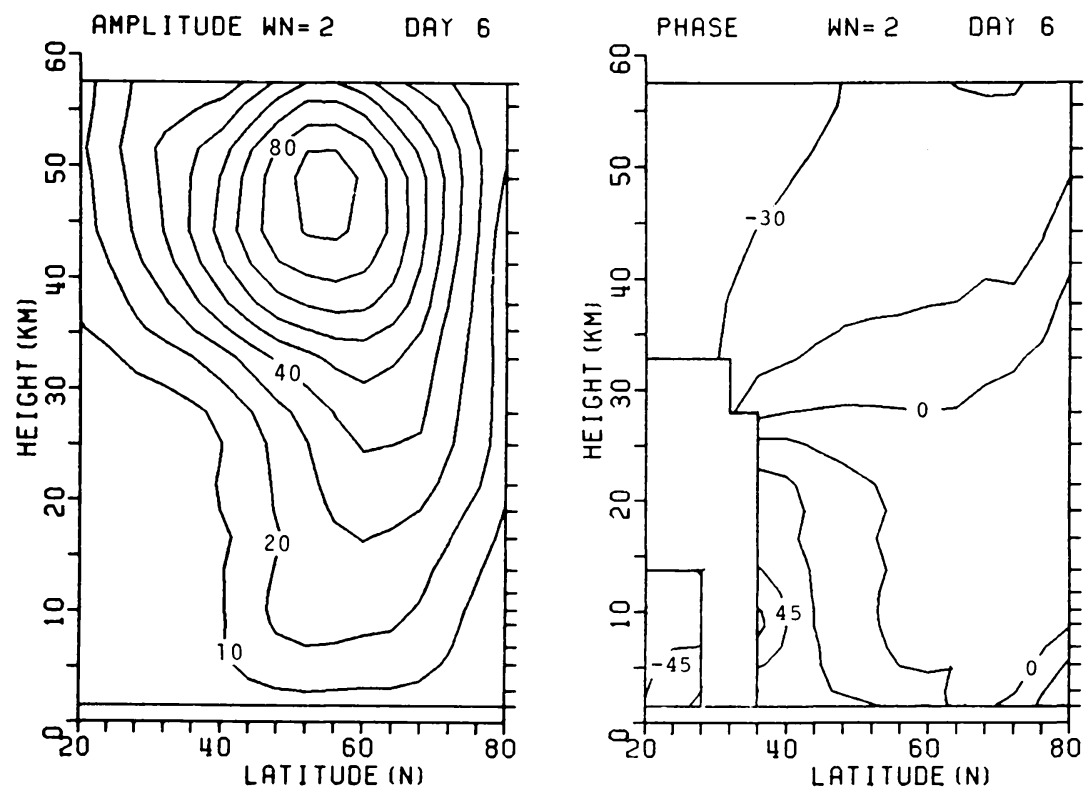

(b)

Fig. 12 
number 2 on day $3,6,25$ and 30 . When the The phase tilted westward with increasing height. amplitude on day 3 is compared with the mean On day 6 when wavenumber 2 became intense zonal wind profile on day 2 (sce Fig. 8(a)), an in activity, the position of a amplitude maximum amplitude maximum takes slightly south of the $(90 \mathrm{dam})$ almost agrees with that of wavenumber maximum westerly jet and a weak amplitude 1 small amplitude at the same day (not shown region in the lower latitude stratosphere takes a here) and the phase tilts with height had become corresponding position of a westerly minimum. weak since day 3 . On day 25 , the position of a
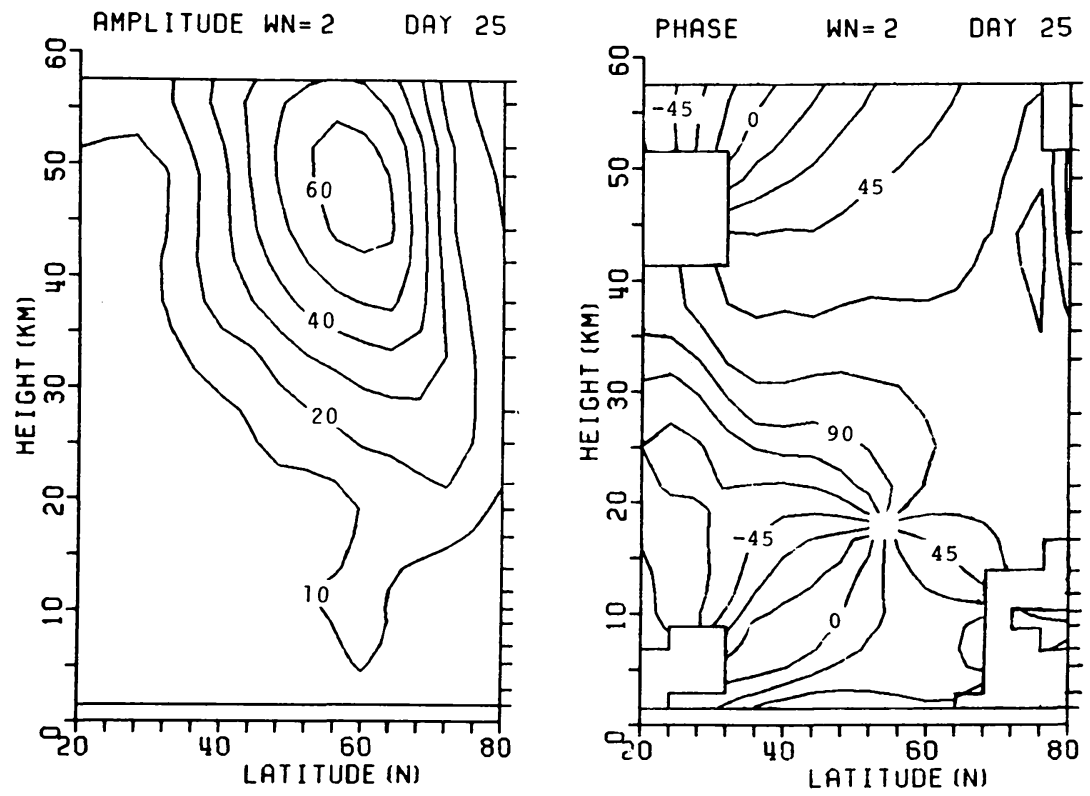

(c)
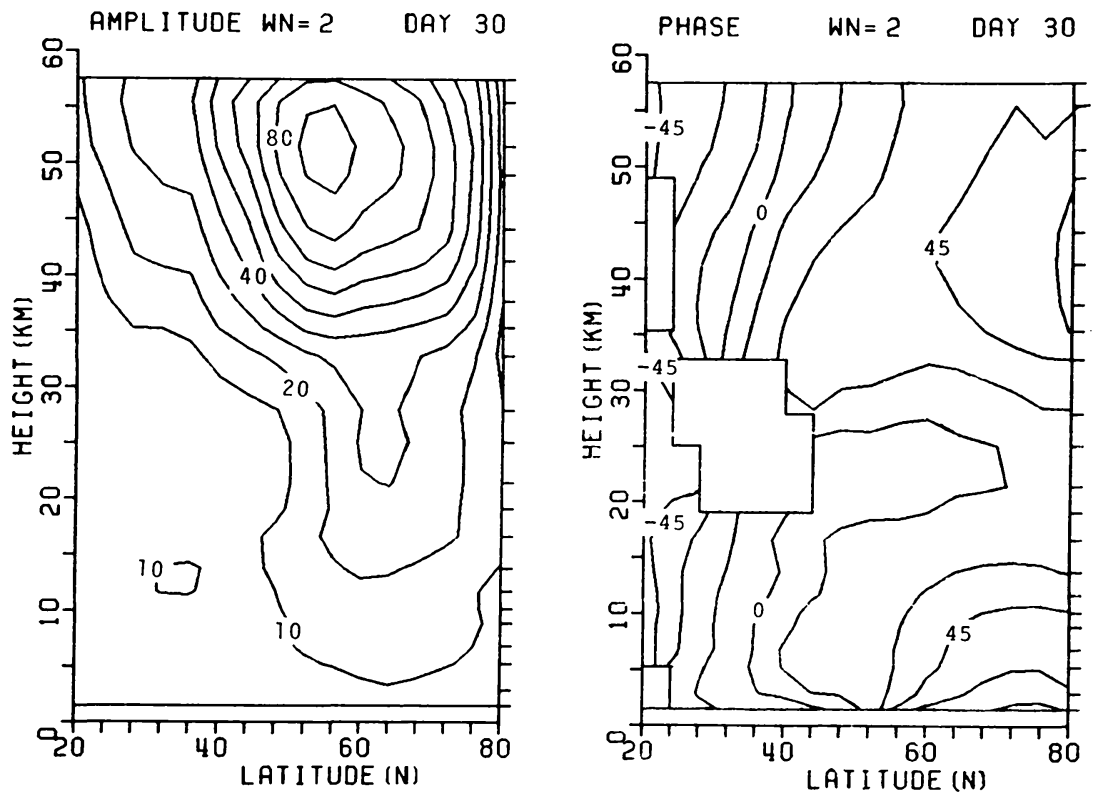

(d)

Fig. 12 As in Fig. 10 but for wavenumber 2 on day 3(a), day 6(b), day 25(c) and day 30 (d). 
wavenumber 2 maximum (60 dam) in the stratosphere also agrees approximately with that of wavenumber 1 amplitude minimum at the same day (see Fig. 11(b)). The relation between wavenumber 1 and 2 amplitude structure around day 6 and day 25 mentioned earlier in the timesections has been reaffirmed here in the meridional plane. The phase structure is somewhat complex. On day 30 when wavenumber 2 be- came most intense $\left(90 \mathrm{dam}\right.$ at $\left.55^{\circ} \mathrm{N}, 50 \mathrm{~km}\right)$ during the wavenumber 1 decay after Warming 2 , the position of the amplitude maximum corresponds approximately to that of wavenumber 1 minimum. The phase gradient directed equatorward in the upper stratosphere.

Fig. 13 shows meridional structure of wavenumber 3 on day 14 and 33 when the wavenumber 3 disturbance was intense. On both days,
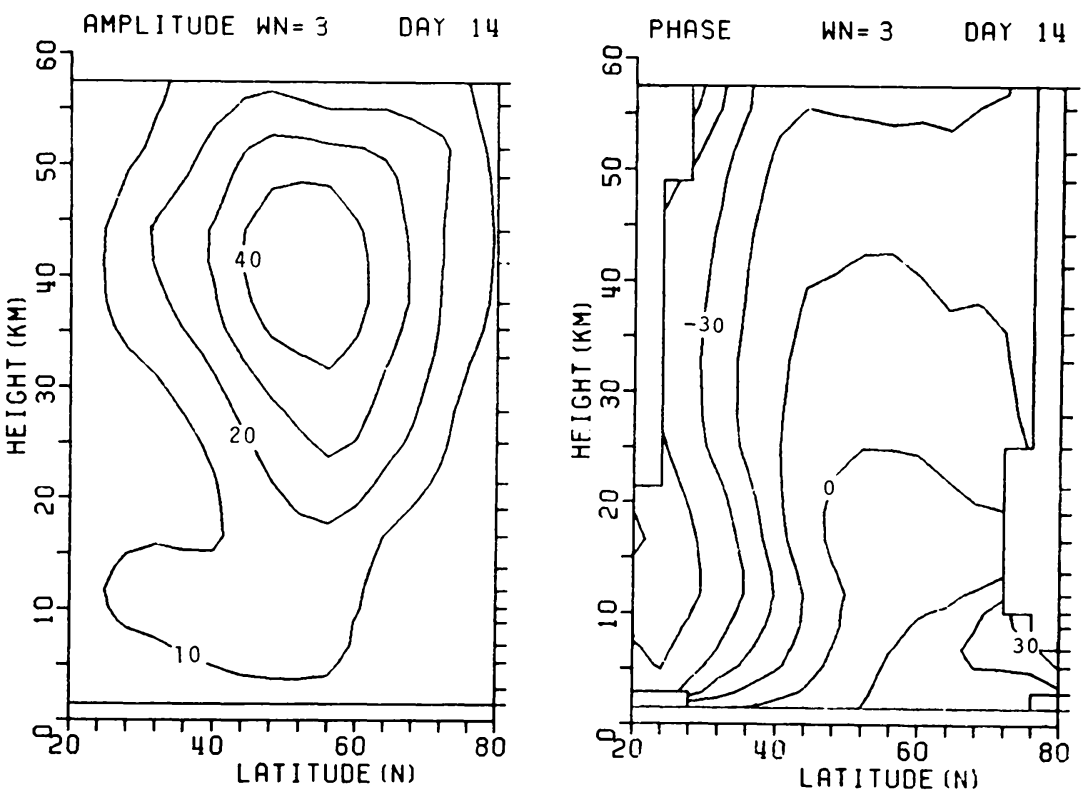

(a)
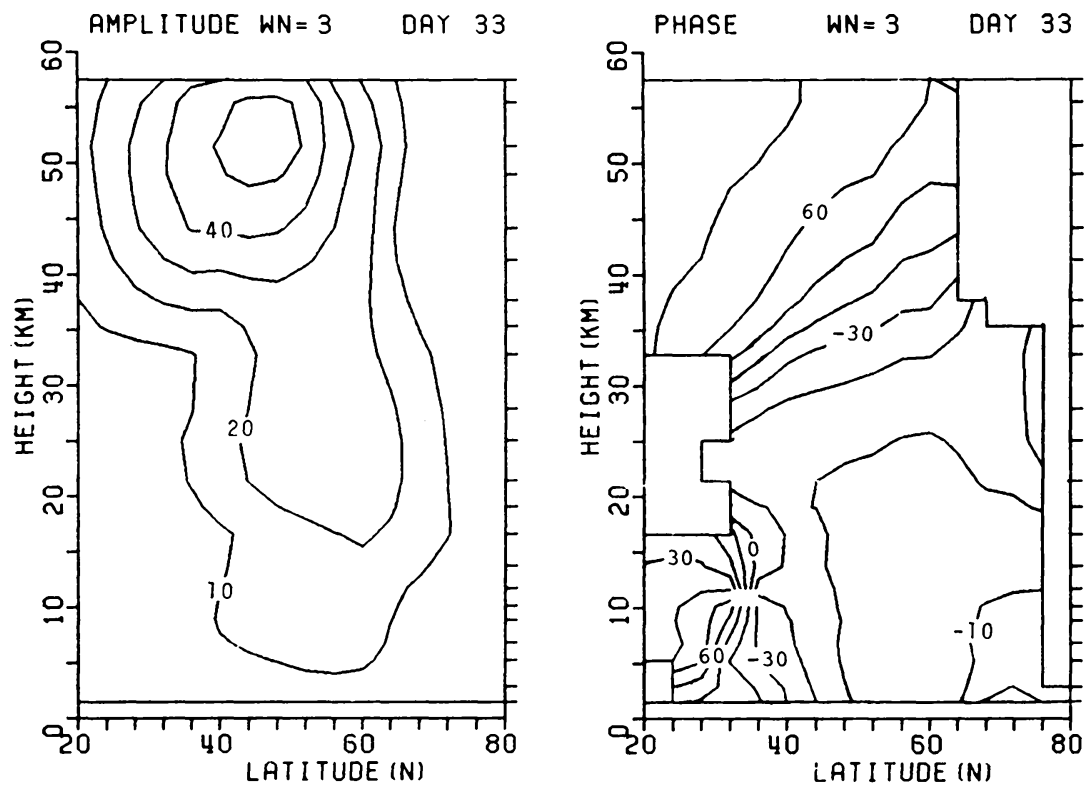

(b)

Fig. 13 As in Fig. 10 but for wavenumber 3 on day 14(a) and day 33(b). 
we can see westward tilts with increasing height. The levels of amplitude maxima of wavenumber 3 on both days coincide approximately with those of wavenumber 1 before 5 days (see Figs. 10(b) and $11(\mathrm{c})$ ) when the wavenumber 1 was most intense. The amplitude maxima of wavenumber 3 are situated more equatorward in latitude.

\section{Momentum budget}

In order to see the interaction between the mean zonal flow and eddy motions, especially to examine the effect of eddies on the evolution of the mean zonal flow, the zonal mean momentum equation appropriate to the quasi-geostrophic motion,

$$
\begin{aligned}
\frac{\partial}{\partial t} \bar{u}= & 2 \Omega \sin \theta \cdot \bar{v} \\
& -\frac{1}{a \cos ^{2} \theta} \frac{\partial}{\partial \theta}\left(\overline{u^{\prime} v^{\prime}} \cos ^{2} \theta\right)
\end{aligned}
$$

is used, where $t$, time; $\theta$, latitude; $a$, the earth's radius; $\Omega$, the earth's rotation rate; $u$, eastward velocity; $v$, northward velocity; “-_, zonal mean; " ", deviation from zonal mean, respectively. The zonal mean momentum acceleration term $(\partial / \partial t) \bar{u}$ and the momentum flux convergence term $-\left(1 / a \cos ^{2} \theta\right)(\partial / \partial \theta)\left(u^{\prime} v^{\prime} \cos ^{2} \theta\right)$ are evaluated by geostrophic relation. The Coriolis torque term $2 \Omega \sin \theta \cdot \bar{v}$ is here treated as the residual of the remaining terms in the equation (2), following O'Neill and Taylor (1979) who studied the 1976/ 77 major stratospheric warming using conventional radiosonde data below $10 \mathrm{mb}$.

Fig. 14 shows meridional cross-sections of the mean zonal wind acceleration term, the momentum flux convergence term and the Coriolis torque term on day 3 and 9 . On day 3 in the upper stratosphere, we can see easterly accelerations in lower latitudes while westerly accelerations in higher latitudes. The contribution of the two terms is complex. On day 9, the area of easterly accelerations approximately coincides with that of negative Coriolis torque. The decelerations of mean flow perhaps comes almost from wavenumber 1 component regarding the structure on this day (see Fig. 10(b)).

Fig. 15 shows meridional distributions of the three terms on day 24, 26 and 28. On day 24 in the upper stratosphere, there occurred easterly accelerations in middle latitudes while westerly accelerations in higher latitudes. The pattern of these accelerations seems to be similar to that of the momentum flux convergence, distinguished from the case on day 3 . The magnitudes of the net accelerations and these two terms as functions of latitude at $1 \mathrm{mb}$ on day 24 are shown in Fig. 16 together with those of the momentum flux convergence terms for wavenumber 1 and 2. At middle latitudes where the easterly accelerations were appreciable, both terms contribute to the decelerations. But the eddy momentum flux convergence played an important role in the evolution of mean flow. Wavenumber 2 is found to make a major contribution to the total momentum flux convergence as expected from the structure of the disturbances around day 24 in section 4. On day 26, a large area of easterly accelerations appeared. Generally in the stratosphere the easterly accelerations come from the predominance of the negative Coriolis torque over the momentum flux convergence in higher latitudes while in lower latitudes from that of the momentum flux divergence. On day 28 , the most intense easterly accelerations occurred in the higher latitude stratosphere with the maximum value of about $25 \mathrm{~m} \mathrm{~s}^{-1}$ day $^{-1}$ at the stratopause level. The decelerations come from the large negative Coriolis torque dominating over the positive momentum flux convergence. This Coriolis torque may be due to the secondary meridional circulation induced by vertically propagating planetary waves. The meridional cell was first shown by Miyakoda (1963) and was interpreted theoretically by Matsuno (1971). The equatorward mean flow is induced mainly by wavenumber 1 component in this case because of its large activity and phase structure on day 28 (see Fig. 11(c)), though cannot be confirmed since the Coriolis term cannot be separated for each wavenumber component in this residual method. It is interesting that the area of easterly accelerations near $60^{\circ} \mathrm{N}$ below $20 \mathrm{~km}$ including the troposphere is observed and agrees with the momentum flux divergence area and the positive Coriolis term in the area could be interpreted as due to northward mean flow in the rear edge of vertically propagating planetary waves discussed theoretically by Uryu (1974).

Both terms in the right hand side of equation (2) were large and nearly balanced during strong accelerations so that the net accelerations was determined by subtle differences of the two terms. This point agrees with Holton (1976)'s numerical experiment and O'Neill and Taylor (1979)'s data analysis. And generally in the upper stratosphere there was positive momentum flux convergence in higher latitudes while negative one (divergence) in lower latitudes, the reverse relation held in 

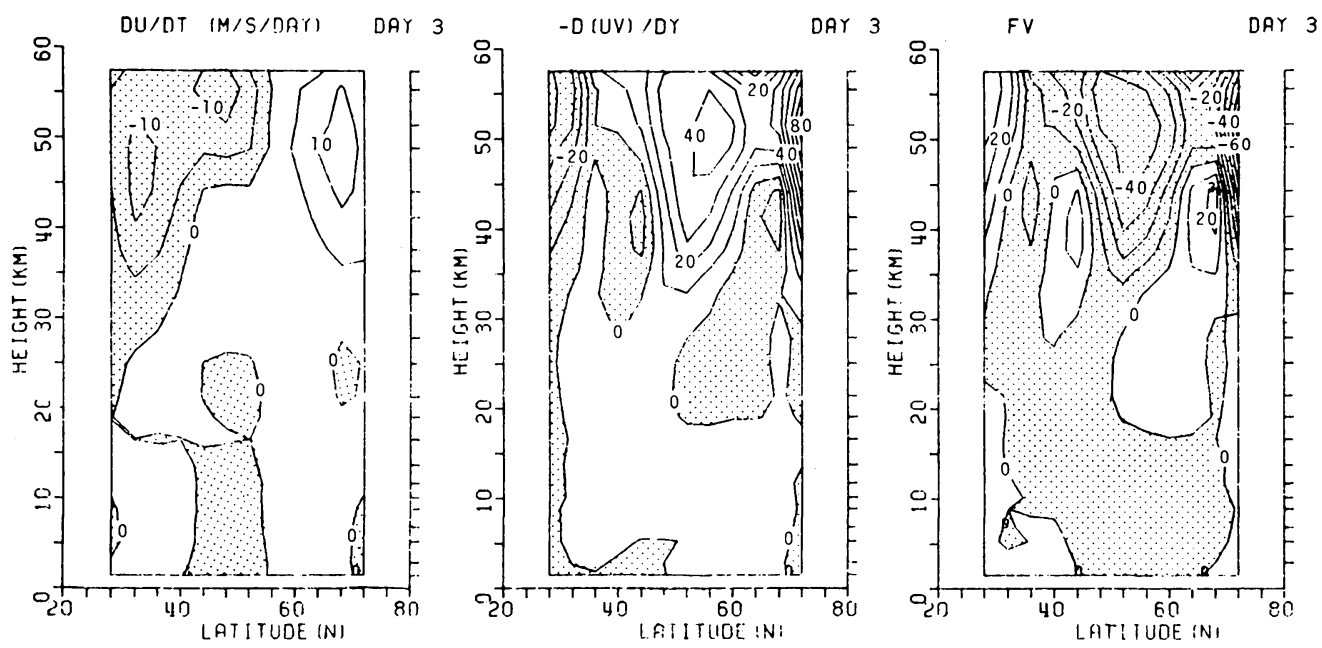

(a)
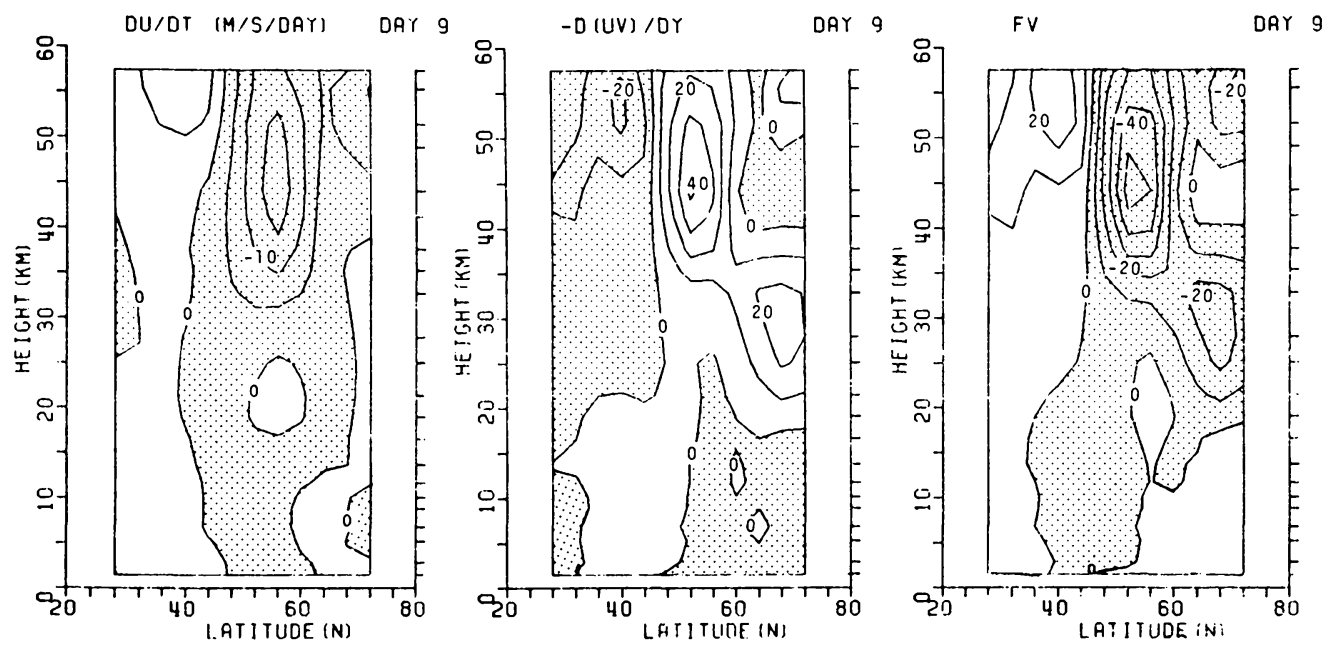

(b)

Fig. 14 Latitude-height sections of the zonal mean flow acceleration $\partial \bar{u} / \partial t$, eddy momentum flux convergence $-\frac{1}{a \cos ^{2} \theta}-\frac{\partial}{\partial \theta}\left(u^{\prime} v^{\prime} \cos ^{2} \theta\right)$ and Coriolis torque $2 \Omega \sin \theta \cdot \bar{v}$ on day 3 (a) and day 9 (b) (units in $\mathrm{ms}^{-1} \mathrm{day}^{-1}$ ).

the Coriolis torque term. O'Neill and Taylor (1979) showed that for the 1976/77 major warming the wind reversal at all levels from the surface to the $10 \mathrm{mb}$ level during its final phase was related to the momentum flux divergence, mainly due to wavenumber 1 disturbances. As for this 1973 Warming 2, the wind reversal did not occur below about $20 \mathrm{~km}$ (see Figs. 4 and 9) and though the mean flow acceleration around day 24 comed approximately from the predominance of the momentum flux convergence term, the most intense easterly accelerations in high latitudes around day 28 was due to the predominance of the negative Coriolis torque. As for the role of the two terms in the upper stratosphere in Warming 2, the similar conclusions were attained by Crane (1979) in terms of energetics.

\section{Quasi-geostrophic potential vorticity gradient}

Basically the amplification of wavenumber 1 seems to have played a most important role in bringing about the circulation reversal corresponding to Warming 2, as discussed in section 4 and 5. Here will be discussed the problem why the 

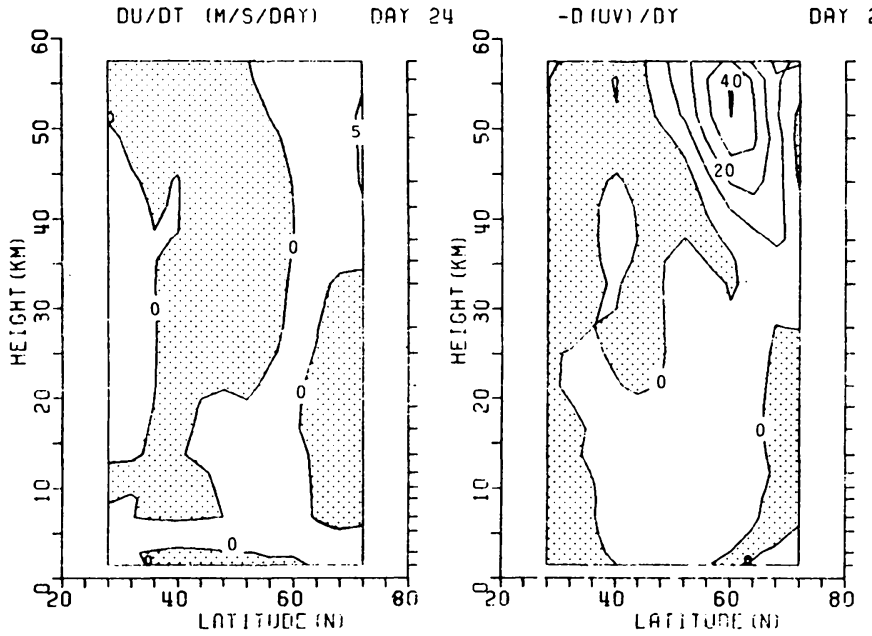

DAY $24 \quad F V$

DAY 24

(a)
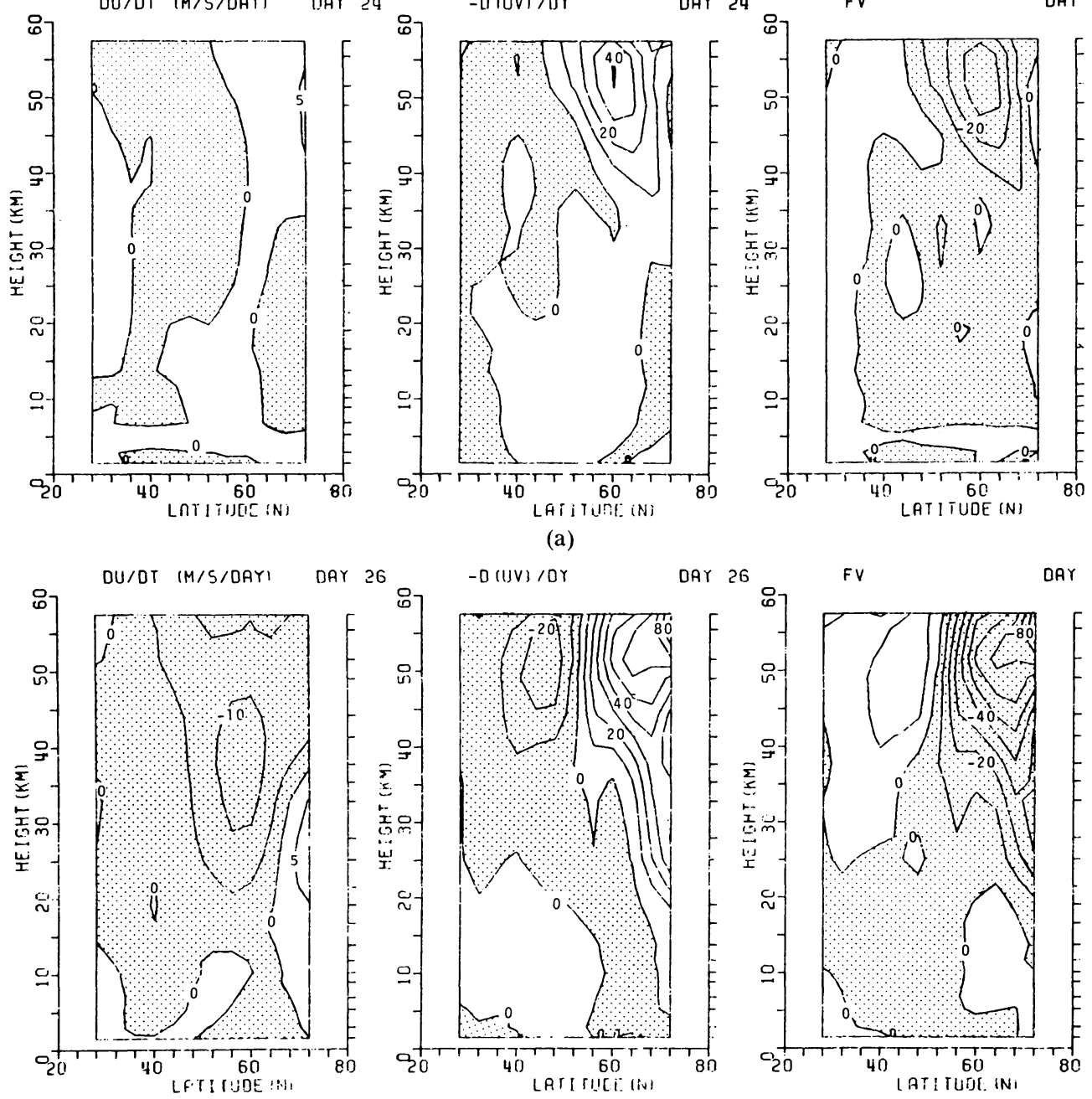

(b)
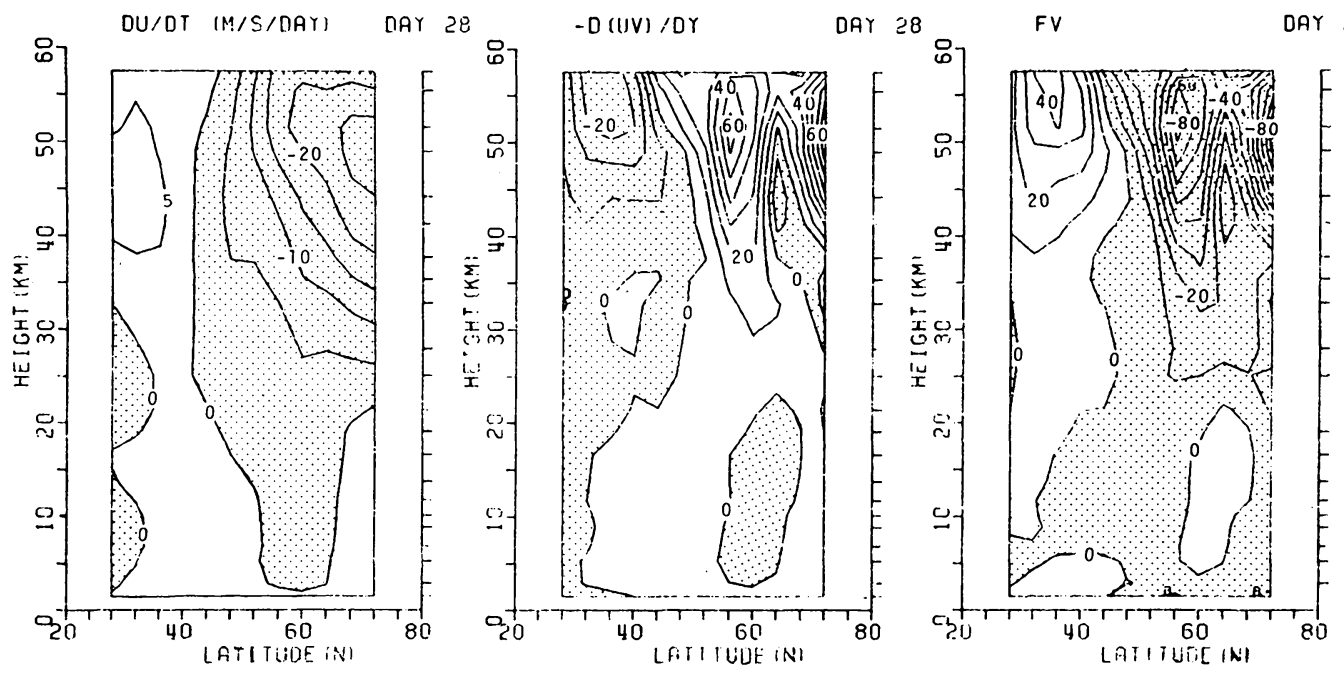

(c)

Fig. 15 As in Fig. 14 but for on day 24 (a), day 26 (b) and day 28 (c). 
DAY 241 MB

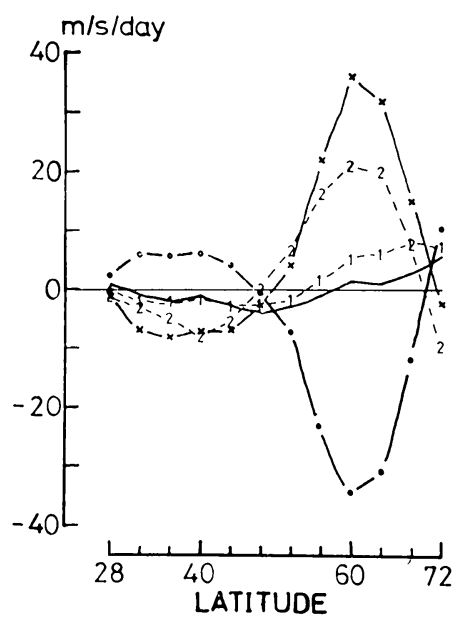

Fig. 16 Latitudinal distribution of net acceleration (thick solid line), total horizontal eddy momentum flux convergence $(-\times-\times-)$ together with momentum flux convergence for wavenumber 1 $(-1--1--)$ and wavenumber 2 $(-2--2--)$, and Coriolis torque $(-\bullet-\bullet-)$ at $1 \mathrm{mb}$ on day 24 .

wavenumber 1 disturbances amplified preceding Warming 2. Let's remember that the wavenumber 1 amplitude maximum propagated vertically from the tropospheric lower levels from about day 22 to day 28 (see Figs. 6(a) and 11) and before the wavenumber 1 amplification from about day 13 through 10 days continued the similar mean zonal wind profile which has a westerly minimum region in the middle latitude upper stratosphere (see Figs. 4(b), 5(a), 8 and 9). In order to investigate the effect of mean zonal wind profile on the planetary wave propagation, we calculate the latitudinal gradient of zonal mean quasi-geostrophic potential vorticity (after Matsuno, 1970),

$$
\begin{aligned}
& \frac{1}{a} \frac{\partial q}{\partial \theta}=\frac{\Omega}{a} \cos \theta\left\{2+2 \omega *-\omega *_{\theta \theta}\right. \\
& \left.\quad+3 \tan \theta \omega *_{\theta}-\left(\frac{2 \Omega a}{N H}\right)^{2} \sin ^{2} \theta\left(\omega *_{z z}-\omega *_{z}\right)\right\}
\end{aligned}
$$

where $\quad \omega^{*}=\frac{\bar{u}}{a \cos \theta} / \Omega$

the ratio of angular velocity of mean zonal wind $\bar{u}$ (relative motion with respect to the rotating earth) to the earth's rotation rate $\Omega$ (this nondimensional quantity $\omega^{*}$ corresponds to Rossby number of planetary-scale motion); $z$, a measure of height $\left(=-\ln \left(p / p_{s}\right)\right.$, where $p$, pressure; $p_{s}$, a constant reference pressure); $N$, Brunt-Väisälä frequency (here adopted a constant value of $\left.2 \times 10^{-2} \mathrm{sec}^{-1}\right)$ and $H$, scale height $(7 \mathrm{~km})$. Other notations were defined below equation (2) in section 5. The quantity $(1 / a)(\partial q / \partial \theta)$ is the $\beta$ effective which corresponds to a restoring force of planetary Rossby wave including not only planetary vorticity gradient $\beta$ but also mean flow curvature and shear.

Fig. 17 shows $(1 / a)(\partial q / \partial \theta)$ with a unit of $\Omega / a$ (hence the planetary vorticity gradient $\beta$ is $2 \cos \theta)$ on day 2 and 19 in the meridional plane. $(1 / a)(\partial q / \partial \theta)$ on day 19 , which is adopted as a representative preceding the wavenumber 1 amplification corresponding to Warming 2, has negative values at 3 places in the meridional plane (see the mean wind profile on day 19 in Fig. 9(a)); the first around $55^{\circ} \mathrm{N}$ and $50 \mathrm{~km}$ which comes from the strong positive curvature of the wind profile in the latitudinal direction together with the negative vertical shear, the second in the lower latitude stratosphere and the third in the tropospheric high latitudes both of which come from the positive curvature in both the latitudinal and vertical directions. A positive maximum in the high latitude middle stratosphere owes its existence to the negative curvature of the mean zonal wind in both the latitudinal and vertical directions. All these characteristics stated above for $(1 / a)(\partial q / \partial \theta)$ on day 19 comes from the appearance of a westerly jet maximum near $40 \mathrm{~km}$ in high latitudes. On day 2 when the wind profile is more similar to that of normal winter (see Fig. 8(a)), the characteristics of the distributions for $(1 / a)(\partial q / \partial \theta)$ may be similar to that of $(1 / a)(\partial q / \partial \theta)$ calculated by Matsuno (1970) for the normal winter wind model, except for the larger values of day 2 and the profile of day 2 as a whole lying in higher latitudes than Matsuno's.

It is speculated that during pre-warming period the planetary wave's energy was confined to the high latitude region with large positive $(1 / a)$ $(\partial q / \partial \theta)$ surrounded by the negative one and then had strong amplification. Tung and Lindzen (1979) showed that in order to have planetary waves of wavenumber 1 and 2 resonant, a second stratospheric westerly maximum must be created at approximately the $40 \mathrm{~km}$ level so that the waves are evanescent above the middle stratosphere. Though they studied the case of an atmosphere with mean winds only varying with height on a mid-latitude $\beta$-plane centered at 


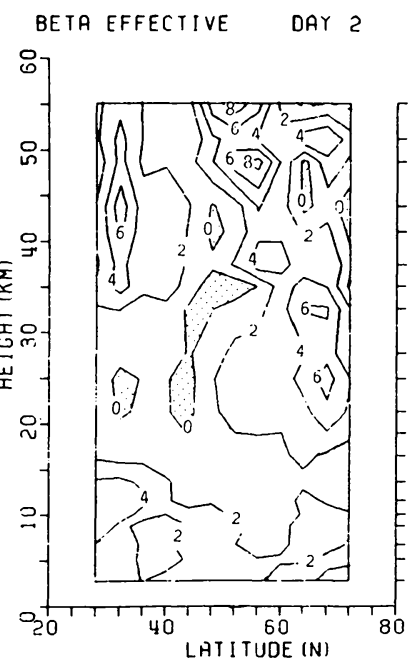

(a)

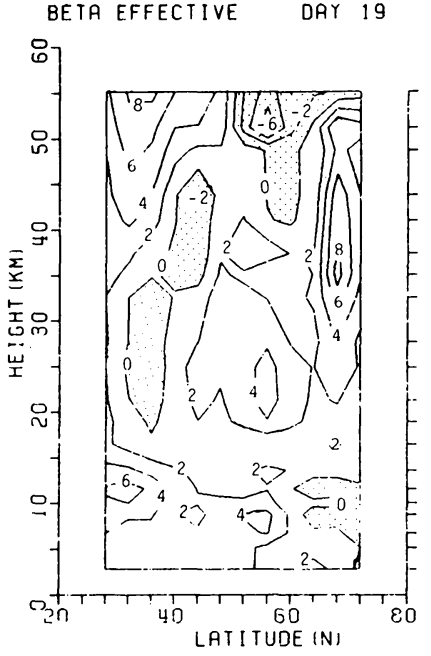

(b)

Fig. 17 Latitude-height sections of latitudinal gradient of zonal mean quasi-geostrophic potential vorticity $\partial q / a \partial \theta$ with units in $\Omega / a$ on day 2 (a) and day 19 (b). Contour lines are drawn with 2 unit interval. Negative values are stippled.

$45^{\circ} \mathrm{N}$, their interpretation of planetary wave amplification preceding the sudden warming basically as resonance may be valid for the 1973 Warming 2 case, in view of the continuation of the characteristic profile of mean zonal wind before the wavenumber 1 amplification. As regards the predominance of wavenumber 1 , but not wavenumber 2 , it is not well understood but we can speculate that the wavenumber 1 type major sudden warming is apt to occur when the warming is considered to be a phenomenon of the whole upper atmosphere, associated with the vertical propagation of planetary waves up to the mesospheric levels. In fact, no wavenumber 2 type major warming has been detected so far from the satellite observations up to the upper stratosphere, except for the third warming of 1979. Inability of wavenumber 2 to generate a major warming by itself was also suggested by Labitzke (1977) using conventional radiosonde data.

\section{Concluding remarks}

The use of satellite data is adequate for the study of sudden stratospheric warming because of its spatial and temporal resolutions. In order to examine the 1973 sudden warming in dynamical aspects, geopotential heights have been retrieved from SCR radiances by a regression method. Detailed descriptions of mean zonal wind and planetary-scale geopotential height disturbances during the major sudden warming in the troposphere, stratosphere and lower mesosphere have been performed in the present study.

The results obtained in the present analysis are summarized as follows;

(1) From the survey of global zonal mean temperature field of 1972/73 northern hemisphere winter by raw radiance data, two mid-winter warmings were detected. By examining the previous studies which used satellite radiance data, it is indicated that the sudden warming occurs in pairs with the interval of about two weeks and the second warming begins at the higher temperatures which is attained by the first warming than the first warming begins.

(2) A large easterly area appeared in the stratospheric higher latitudes in Warming 2 while not in Warming 1. The easterly flow first appeared in the upper stratospheric middle latitudes and the decelerations seem to come mainly from the predominance of eddy momentum flux divergence by wavenumber 2 disturbances. Eventually the strong easterly winds appeared at high latitudes and moved downward to the $20 \mathrm{~km}$ level. During the intense easterly accelerations the amplitude of wavenumber 1 became intense and the decelerations in higher latitudes are considered to come from the predominance of the Coriolis force acting on the equatorward mean 
meridional flow induced mainly by the wavenumber 1 which propagated upward from the lower troposphere to the middle stratosphere, as first discussed by Matsuno (1971). Thus the interchanging role of wavenumber 1 and wavenumber 2 was played in the decelerations of the stratospheric westerly flow. None the less the intense amplification of wavenumber 1 propagating upward seems to play a major role in generating the stratospheric circulation reversal in Warming 2.

(3) Wavenumber 1 disturbances were quasistationary in phase and had westward tilts with increasing height in most of the period analyzed and propagated upward during pre-warming period. Wavenumber 2 progressed eastward during the weak amplification and the phase structure in the meridional plane was complex and there is no indication of upward propagation of wavenumber 2 . Wavenumber 3 propagated upward from the tropospheric lower levels to the stratosphere about 5 days later than the wavenumber 1 upward propagation, with eastward progression conserving westward tilts with height.

(4) It is shown that after Warming 1 through about 10 days continued the characteristic mean wind profile that a westerly maximum situated near $40 \mathrm{~km}$ in high latitudes is cut off from another westerly jet in the lower latitude lower mesosphere by a wind minimum region in the middle latitude upper stratosphere. By the curvature and shear effects of the wind profile, quasi-geostrophic potential vorticity latitudinal gradient $(1 / a)(\partial q / \partial \theta)$ which corresponding to the restoring force of planetary Rossby waves had a feature of the high latitude stratospheric region of maximum positive value surrounded by the negative value region. It is speculated that such a wind profile accumulated the wavenumber 1 wave energy in the high latitude stratosphere and brought about the resonant amplification of the planetary waves, as recently discussed by Tung and Lindzen (1979).

In order to know the significance of the descriptions given for the 1973 major warming, this type of dynamical analysis is desired for other warming cases. Moreover we can depict the planetary wave-mean flow interactions more clearly in terms of so-called Eliassen-Palm wave flux (pseudo-angular momentum flux, Andrews and McIntyre, 1976; Sato, 1980) and we are now engaged in the analysis. On the basis of theoretical study of Tung and Lindzen (1979), we speculated that the planetary waves of wave- number 1 resonated in response to a characteristic mean wind profile, but in their model the mean winds only vary with hcight and do not change in time. Therefore, in order to test the hypothesis of resonance, the extension of their work is required. The bchavior of wavenumber 2 disturbances seems not to be accounted for in terms of the theory of forced wave-zonal flow interaction. The study of the effect of nonlinear interaction including wave-wave interaction may be required for more complete understanding of the phenomenon of sudden warming.

\section{Acknowledgements}

I wish to express my hearty thanks to Prof. I. Hirota of the Geophysical Institute of Kyoto University for his continuing guidance and valuable discussions throughout this work. I am also grateful to Prof. R. Yamamoto for his encouragement and the members of Meteorological Research Laboratory, especially to Mr. K. Kawahira for his continuing discussions and $\mathrm{Mr}$. $\mathrm{H}$. Kobayashi for his help in handling the NMC data. It is a pleasure to acknowledge the stimulative discussions with $\mathrm{Mr}$. $\mathrm{H}$. Itoh of Wakayama University.

Thanks are also due to the department of Atmospheric Physics of the University of Oxford for providing the Nimbus 5 SCR data and NCAR for the NMC geopotential height data. The computations in the present study were performed with the use of the FACOM M-190 computer at the Data Processing Center of Kyoto University.

\section{References}

Abel, P. G., Ellis, P. J., Houghton, J. T., Peckham, G., Rodgers, C. D., Smith, S. D. and Williamson, E. J., 1970: Remote sounding of atmospheric temperature from satellites II. The selective chopper radiometer for Nimbus D. Proc. Roy. Soc. Lond. A. 320, 35-55.

Andrews, D. G. and McIntyre, M. E., 1976: Planetary waves in horizontal and vertical shear: the generalized Eliassen-Palm relation and the mean zonal accelerations. J. Atmos. Sci., 33, 20312047.

Barnett, J. J., 1974: The mean meridional temperature behaviour of the stratosphere from November 1970 to November 1971 derived from measurements by the Selective Chopper Radiometer on Nimbus IV. Quart. J. Roy. Met. Soc., 100, 505-530.

, Harwood, R. S., Houghton, J. T., Morgan, C. G., Rodgers, C. D. and Williamson, E. J., 
1975: Comparison between radiosonde, rocketsonde, and satellite observations of atmospheric temperatures. Quart. J. Roy. Met. Soc., 101, 423-436.

Charney, J. G. and Drazin, P. G., 1961: Propagation of planetary-scale disturbances from the lower into the upper atmosphere. J. Geophys. Res., 66, 83-109.

Crane, A. J., 1979: Aspects of the energetics of the upper stratosphere during the January-February 1973 major sudden warming. Quart. J. Roy. Met. Soc., 105, 185-206.

Eliassen, A. and Palm, E., 1960: On the transfer of energy in stationary mountain waves. Geophys. Publ. 22, No. 3, 1-23.

Ellis, P., Holah, G., Houghton, J. T., Jones, T. S., Peckham, G., Peskett, G. D., Pick, D. R., Rodgers, C. D., Roscoe, H., Sandwell, R., Smith, S. D. and Williamson, E. J., 1973: Remote sounding of atmospheric temperature from satellites IV. The selective chopper radiometer for Nimbus 5. Proc. Roy. Soc. Lond. A. 334, 149-170.

Fritz, S. and Soules, S. D., 1970: Large-scale temperature changes in the stratosphere observed from Nimbus III. J. Atmos. Sci., 27, 1091-1097.

Hartmann, D. L., 1976: The structure of the stratosphere in the southern hemisphere during late winter 1973 as observed by satellite. J. Atmos. Sci., 33, 1141-1154.

Hirota, I. and Sato, Y., 1969: Periodic variation of the winter stratospheric circulation and intermittent vertical propagation of planetary waves. J. Meteor. Soc. Japan, 47, 390-402.

Holton, J. R., 1975: The dynamic meteorology of the stratosphere and mesosphere. Meteor. Monogr., No. 37, Amer. Meteor. Soc., 218 pp.

- 1976: A semi-spectral numerical model for wave-mean flow interactions in the stratosphere: Application to sudden stratospheric warmings. J. Atmos. Sci., 33, 1639-1649.

Houghton, J. T. and Smith, S. D., 1970: Remote sounding of atmospheric temperature from satellites I. Introduction. Proc. Roy. Soc. Lond. A. 320, 23-33.

Iwashima, T., 1973: Observational studies of the ultra-long waves in the atmosphere (I) Part 1. Daily behaviour of the quasi-stationary and travelling ultra-long waves during the stratospheric sudden warming. J. Meteor. Soc. Japan, 51, 209-229.

Labitzke, K., 1977: Interannual variability of the winter stratosphere in the northern hemisphere. Mon. Wea. Rev., 105, 762-770.

Leovy, C. B. and Webster, P. J., 1976: Stratospheric long waves: Comparison of thermal structure in the northern and southern hemispheres. J. Atmos. Sci., 33, 1624-1638.

Matsuno, T., 1970: Vertical propagation of stationary planetary waves in the winter northern hemisphere. J. Atmos. Sci., 27, 871-883.

, 1971: A dynamical model of the stratospheric sudden warming. J. Atmos. Sci., 28, 1479-1494.

McInturff, R., ed., 1978: Stratospheric warmings: Synoptic, dynamic and general-circulation aspects. NASA Reference Publication 1017, 166 pp.

Miyakoda, K., 1963: Some characteristic features of winter circulation in the troposphere and lower stratosphere. Tech. Rept. 14, The Univ. of Chicago, $93 \mathrm{pp}$.

Muench, H. S., 1965: On the dynamics of the wintertime stratosphere circulation. J. Atmos. Sci., 22, 349-360.

Murgatroyd, R. J., 1969: The structure and dynamics of the stratosphere. The Global Circulation of the Atmosphere, Corby, G. A., ed., London, Roy. Meteor. Soc., 159-195.

O'Neill, A. and Taylor, B. F., 1979: A study of the major stratospheric warming of 1976/77. Quart. J. Roy. Met. Soc., 105, 71-92.

Quiroz, R. S., 1977: The tropospheric-stratospheric polar vortex breakdown of January 1977. Geophys. Res. Lett., 4, 151-154.

1979: Tropospheric-stratospheric interaction in the major warming event of JanuaryFebruary 1979. Geophys. Res. Lett., 6, 645-648. and Gelman, M. E., 1972: Direct determination of the thickness of stratospheric layers from single channel satellite radiance measurements. Mon. Wea. Rev., 100, 788-795.

Sato, Y., 1980: Observational estimates of Eliassen and Palm flux due to quasi-stationary planetary waves, to be appeared in J. Meteor. Soc. Japan, 58.

Schoeberl, M. R., 1978: Stratospheric warmings: Observations and theory. Rev. Geophys. Space Phys., 16, 521-538.

- Geller, M. A. and Avery, S. K., 1979: The structure of stationary planetary waves in winter: A correction. J. Atmos. Sci., 36, 365-369.

Simmons, A. J., 1978: Some effects of meridional shear and spherical geometry on long stratospheric waves. Quart. J. Roy. Met. Soc., 104, 595-614.

Tung, K. K. and Lindzen, R. S., 1979: A theory of stationary long waves. Part II: Resonant Rossby waves in the presense of realistic vertical shears. Mon. Wea. Rev., 107, 735-750.

Uryu, M., 1974: Mean zonal flows induced by a vertically propagating Rossby wave packet. $J$. Meteor. Soc. Japan, 52, 481-490. 


\title{
1973 年突然昇温時, 対流圈・成㞒圈における平均帯状流および 惑星規模擾乱の振舞
}

\author{
神沢博

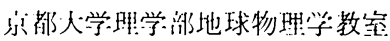

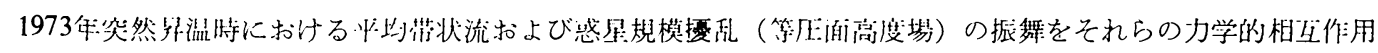

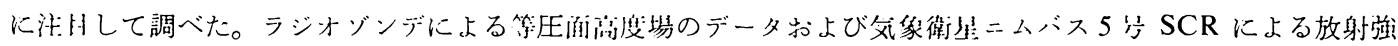

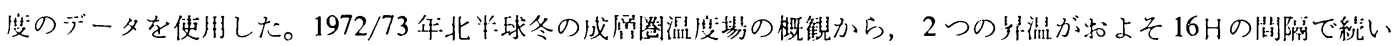

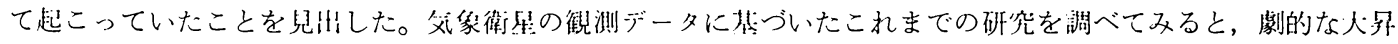

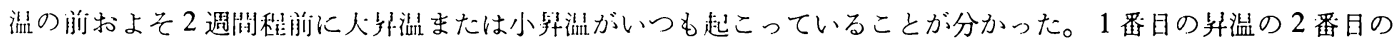
罗温に対する影管が注目される。

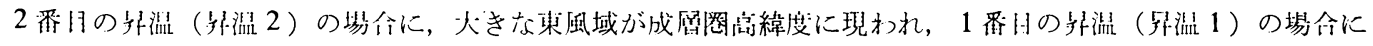

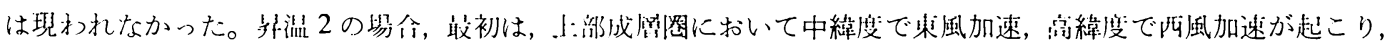

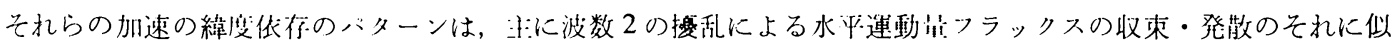

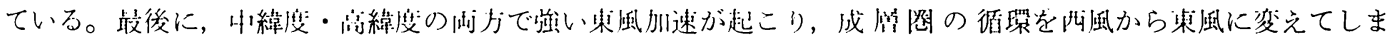

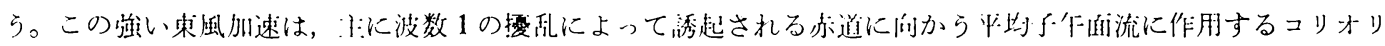

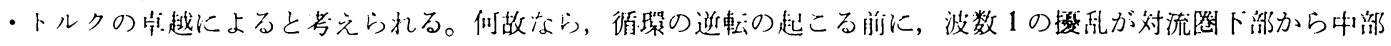

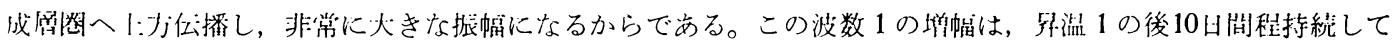

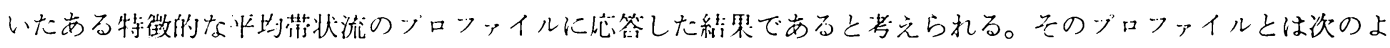

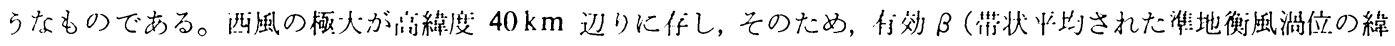
度微分）が大きな作の值を取る领域が，们の領域に明まれている。このことから，この波数 1 の增幅は，Tung.

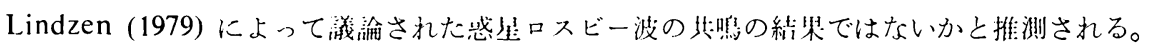

